Environmental Management

Elsevier Editorial System(tm) for Journal of

Manuscript Draft

Manuscript Number: JEMA-D-18-02917R1

Title: Outsourcing natural resource requirements within China

Article Type: Research Article

Keywords: Embodied exergy; Natural resource footprint; Multi-regional input-output analysis; Consumption-based accounting; Chinese regions

Corresponding Author: Dr. Bo Zhang,

Corresponding Author's Institution: China University of Mining \& Technology (Beijing)

First Author: Yaowen Zhang

Order of Authors: Yaowen Zhang; Ling Shao; Xudong Sun; Mengyao Han; Xueli Zhao; Jing Meng; Bo Zhang; Han Qiao

Abstract: Consumption demands are final drivers for the extraction and allocation of natural resources. This paper investigates demand-driven natural resource requirements and spatial outsourcing within China in 2012 by using the latest multi-regional input-output model. Exergy is adopted as a common metric for natural resources input. The total domestic resource exergy requirements amounted to 125.5 EJ, of which the eastern area contributed the largest share of 44.5\%, followed by the western area (23.9\%), the central area (23.0\%) and the northeastern area $(8.6 \%)$. Investment was the leading final demand category, accounting for $52.9 \%$ (66.4 EJ) of national total embodied resource use (ERU). The total trade volumes of embodied resource were equivalent to 69.6\% of the total direct resource input (DRI), mostly transferred from the central and western regions such as Inner Mongolia, Shanxi, Shaanxi and Xinjiang to the eastern regions such as Jiangsu, Zhejiang, Guangdong and Shanghai. The northeastern and eastern areas had physical net imports of 1213.5 PJ and 38452.6 PJ, while the central and western inland areas had physical net exports of 6364.5 PJ and 33301.5 PJ, respectively. Shanghai, Beijing, Zhejiang, Jiangsu and Guangdong had prominent ERUs which respectively were 101.6, 12.6, 11.7, 8.4 and 4.3 times of their DRIs. The ERUs of Inner Mongolia, Shaanxi, Shanxi, Ningxia and Guizhou were equal to only $17.6 \%, 25.3 \%, 27.9 \%, 46.0 \%$ and 50.2\% of their DRIs, respectively. Regional uneven development resulted in imbalanced resource requirements across China. The findings can provide a deep understanding of China's resource-driven economic development mode, and contribute to reducing regional resource footprints and their environment outcomes under the "new normal economy". 


\title{
Outsourcing natural resource requirements within China
}

\author{
Yaowen Zhang ${ }^{a}$, Ling Shao ${ }^{b}$, Xudong Sun ${ }^{a}$, Mengyao Han ${ }^{c}$, Xueli Zhao ${ }^{a}$, Jing \\ Meng ', Bo Zhang ${ }^{\text {a,e,* }}$, Han Qiao ${ }^{\text {f,* }}$ \\ ${ }^{a}$ School of Management, China University of Mining \& Technology (Beijing), Beijing 100083, P.R. \\ China
}

${ }^{b}$ School of Humanities and Economic Management, China University of Geosciences, Beijing 100083,

China

${ }^{c}$ Institute of Geographic Sciences and Natural Resources Research, Chinese Academy of Sciences, Beijing 100101, PR China

${ }^{d}$ Department of Politics and International Studies, University of Cambridge, Cambridge CB3 9DT, UK

${ }^{e}$ Harvard China Project, School of Engineering and Applied Sciences, Harvard University, MA 02138,

United States

${ }^{f}$ School of Economics and Management, University of Chinese Academy of Sciences, Beijing 100190, PR China

\begin{abstract}
Consumption demands are final drivers for the extraction and allocation of natural resources. This paper investigates demand-driven natural resource requirements and spatial outsourcing within China in 2012 by using the latest multi-regional input-output model. Exergy is adopted as a common metric for natural resources input.

\footnotetext{
* Corresponding authors.

E-mail addresses: zhangbo@cumtb.edu.cn (B. Zhang); qiaohan@ucas.ac.cn (H. Qiao).
} 
The total domestic resource exergy requirements amounted to $125.5 \mathrm{EJ}$, of which the eastern area contributed the largest share of $44.5 \%$, followed by the western area $(23.9 \%)$, the central area $(23.0 \%)$ and the northeastern area $(8.6 \%)$. Investment was the leading final demand category, accounting for 52.9\% (66.4 EJ) of national total embodied resource use (ERU). The total trade volumes of embodied resource were equivalent to $69.6 \%$ of the total direct resource input (DRI), mostly transferred from the central and western regions such as Inner Mongolia, Shanxi, Shaanxi and Xinjiang to the eastern regions such as Jiangsu, Zhejiang, Guangdong and Shanghai. The northeastern and eastern areas had physical net imports of 1213.5 PJ and 38452.6 PJ, while the central and western inland areas had physical net exports of $6364.5 \mathrm{PJ}$ and 33301.5 PJ, respectively. Shanghai, Beijing, Zhejiang, Jiangsu and Guangdong had prominent ERUs which respectively were 101.6, 12.6, 11.7, 8.4 and 4.3 times of their DRIs. The ERUs of Inner Mongolia, Shaanxi, Shanxi, Ningxia and Guizhou were equal to only $17.6 \%, 25.3 \%, 27.9 \%, 46.0 \%$ and $50.2 \%$ of their DRIs, respectively. Regional uneven development resulted in imbalanced resource requirements across China. The findings can provide a deep understanding of China's resource-driven economic development mode, and contribute to reducing regional resource footprints and their environment outcomes under the "new normal economy".

Keywords: Embodied exergy; Natural resource footprint; Multi-regional input-output analysis; Consumption-based accounting; Chinese regions 


\section{Introduction}

The extraction and supply of natural resources, especially non-renewable resources, sustains the operation and evolution of human society (Ayres et al., 2003; Warr and Ayres, 2012). China, as the second largest economy with the largest population in the world, has enormous demands of natural resources to drive its fast-growing economy (Brockway et al., 2015; Zhang et al., 2018a). For instance, China is the world's largest primary energy producer, where 44.2 billion tons of raw coal, 3.0 billion tons of crude oil and 1199.7 billion $\mathrm{m}^{3}$ of natural gas were extracted during 2000-2015 (NBSC, 2016). The extensive exploration and intensive uses of natural resources have resulted in adverse effects on the environment, including non-renewable resource depletion, environmental pollution, climate impacts and ecological degradation (Liu et al., 2015; Zhang et al., 2018a). Since 2012, the Chinese society has entered a new development phase under the "new normal economy" (Mi et al., 2017), while the relationships among resource, economy and environment has become more complicated. Effective measures to reduce resource depletion and materials footprint are of great concern to gauge the sustainability of the Chinese society and support policy making.

From a thermodynamics perspective, exergy is defined as "the maximum amount of work that can be produced by a system or a flow of matter or energy as it comes to equilibrium with a reference environment" (Wall, 1977). The exergy of natural resource is its usefulness or quality to cause change and its physical scarcity. Exergy analysis then makes it possible to compare and add all the kinds of natural resources with a single entity, which other measures cannot. In the past two decades, exergy 
method has been widely accepted as a unified and objective measure of natural resources and manmade products, and the scope of resource exergy accounting has been extended from energy carriers to different kinds of resources or materials (Chen et al., 2006; Zhang and Chen, 2010). Previous studies have proved that exergy method is a valuable tool to evaluate natural resource uses in the macro-level socioeconomic system with a solid scientific basis (Chen et al., 2006; Chen and Chen, 2006, 2007a,b,c; Dewulf et al., 2008; Sciubba and Bastianoni, 2008; Shao et al., 2013; An et al., 2014; Valero et al., 2015; Zhang et al., 2018b).

Natural resources are extracted from the environment, then processed and used to produce commodities or services in various industrial sectors along the supply chains. In other words, the extraction of natural resources can be attributed to economic production and consumption activities, as well as embodied (direct plus indirect) resource inputs are required to meet final demands (Zhang et al., 2013). Since the input-output table captures the complex economic linkages among industrial sectors, environmental extended input-output analysis (EEIOA) incorporates resource elements into the socioeconomic context and quantifies how many of the elements in terms of embodied resources have to be consumed through the production process to meet the end use. A series of studies have carried out the input-output analyses for energy and materials consumption of economic activities at different scales (Hawkins et al., 2015). By considering the inter-industry network linkages between resource producers and users, it is possible to attribute the natural resource supply from ecosystem to a specific final demand category. 
In China, the provincial region is the most important administrative unit in policy formulating. Mainland China has 31 provincial-level administrative units, but there are significant differences in both resource endowments and economic development levels among these provincial regions. Since there are fewer barriers in interregional trade than in international trade, China's interprovincial trade plays an important role in redistributing resources and commodities. Liu and Wang (2017) reported that the economic scale of interregional trade increased 29-fold between 1987 and 2007. In 2012, the interprovincial trade scale reached 24574.0 billion CNY, twice bigger than the scale of international imports (Liu et al., 2018). Increasing domestic trade volume has resulted in the fast-growing transfer of resources and commodities along with interregional or intraregional supply chains. Therefore, ignoring interregional trade and the accompanying resource transfer could lead to a misunderstanding of regional real resource requirements and corresponding driving forces.

Multi-regional input-output (MRIO) modeling is the most popular tool to identify inter-dependencies among different regions (Wiedmann, 2009). Existing studies have employed the MRIO models to analyze embodied energy, virtual water, virtual land and embodied emissions (e.g., mercury, $\mathrm{PM}_{2.5}, \mathrm{COD}, \mathrm{CO}_{2}, \mathrm{SO}_{2}$ and $\mathrm{CH}_{4}$ ) in China, particularly focusing on the impacts and effects of interprovincial trade (e.g., Liang et al., 2007; Zhou and Imrua, 2011; Feng et al., 2012, 2013; Meng et al., 2013; Liang et al., 2014; Su and Ang, 2014; Zhang and Anadon, 2014; Zhang and Lahr, 2014; Zhang et al., 2014a,b; Zhang et al., 2013, 2015a,b; Liu et al., 2015; Liang et al., 2017; Wang et al., 2017; Shao et al., 2018; Wang et al., 2017, 2018; Yang et al., 2018; Zhang et al., 
2018c). Given the diversity of natural resources, an overall account of all types of resource embodied in goods exchange between regions is required. It is necessary to identify interregional trade patterns of embodied resource requirements by an integrative and unified way instead of single resource type. The thermodynamic input-output network models has been used to clarify the resource consumption of a country and resource intensities of specific industrial sectors from the insights of biophysical economics or thermo-economics (e.g., Ukidwe and Bakshi, 2004, 2007; Chen and Chen, 2010, 2011; An et al., 2015; Zhang et al., 2017, 2018a). However, demand-driven natural resource requirements in China at both the national and regional scales remain to be systematically revealed.

This paper aims to illustrate outsourcing resource requirements within China by using the recently available MRIO table and natural resources data for 2012. Exergy is adopted as a common metric for the account of natural resource inputs. All the 31 provincial regions of Mainland China covering Tibet have been included. An overview of regional resource uses associated with production, consumption and interprovincial trade will address the resource requirement patterns throughout entire supply chains from the embodiment perspective. Consumption-based resource accounting will provide a different insight on where to focus policy instrument to reduce resource footprints and environmental outcomes of China's provincial regions.

\section{Methodology and data sources}

\subsection{Resource exergy accounting method}


Exergy method can provide a unified and objective measure to perform the accounting of natural resources (Wall, 1977; Zhang et al., 2018b). For each type of natural resource, its potential usefulness or ability to perform work is expressed by its exergy content (Szargut, 2005). Chemical exergy is used as a unified indicator to quantify the natural resource production. The boundary between the natural ecosystem and socioeconomic system is carefully defined to avoid double accounting. The domestic extraction of natural resources in Mainland China refers to crops, forestry, rangeland and aquatic products, coal, crude oil \& natural gas, ferrous metal ores, nonferrous metal ores, nonmetallic minerals, hydropower, wind power, nuclear power and others. All natural resources can be grouped as agricultural resources, energy minerals, non-energy minerals, and other primary energy resources (see Table 1). Detailed resource exergy coefficients are listed in Table S1.

Table 1

The categories of natural resource extracted in China

\begin{tabular}{ll} 
Category & Content \\
\hline & Crops: rice, wheat, corn, millet, sorghum, bean, potato, peanut, rapeseed, \\
& sesame, flaxseed, sunflower, cotton, hemp, sugarcane, tea leaf, tobacco leaf, \\
Agricultural resources & vegetable, melon, apple, pear, banana, orange, grape, pine apple, red date, \\
& persimmon, landscape fruit, berries \\
& Forestry: timber, bamboo, rubber, pine resin, lacquer, tung-oil seeds, Tea-oil \\
& seeds, forest food
\end{tabular}




\section{Rangeland products: hay}

Aquatic products: seawater aquatic products, freshwater aquatic products

Coal

Energy minerals

$$
\text { Crude oil, natural gas }
$$

Iron ore, copper concentrated, lead concentrated, zinc concentrated, alumina,

Non-energy minerals

Raw salt, pyrite, phosphorus ore, limestone, clay

Other primary energy Hydropower, nuclear power, wind power, other renewable energy

The data of agricultural resources or biomass resources are obtained from China Agricultural Statistical Yearbook (CASY, 2013), China Animal Industry Yearbook (CAIY, 2013) and China Forestry Statistical Yearbook (CFSY, 2013). The hay inputs of rangeland are estimated according to the method in Chen and Chen (2006). To exploit the feed intake from the rangeland by the livestock, the number of different types of livestock is deduced to the sheep unit and one sheep unit feed is about $150 \mathrm{~kg}$ hay annually.

The fossil fuel data are available from China Energy Statistical Yearbook (CESY, 2013). Other primary energy inputs into regional economy refer to hydropower, nuclear power, wind power and other renewable power, which are estimated according to electricity generation data and corresponding electricity generation efficiencies (Zhang et al., 2013, 2015a). The electricity outputs of all the 31 provincial regions are collected or derived from China Electric Power Yearbook (CEPY, 2013).

In addition, the amount of limestone and clay are calculated based on regional cement production data. Relevant data of mineral extraction are available from China 
Industry Statistical Yearbook (CISY, 2013), China Mining Yearbook (CMY, 2013) and China Non-ferrous Metal Statistical Yearbook (CNMY, 2013). Detailed results of natural resource inputs into regional economy in 2012 are listed in Table S2.

\subsection{Multi-regional input-output models}

The MRIO table for China 2012 employed in this study is compiled by the scholars from Chinese Academy of Science and National Bureau of Statistics of China (Liu et al., 2018). This table is the latest available MRIO table, which is a continuation of the MRIO tables for China 2007 and 2010. Previous studies have proved the authority of such MRIO tables to explore the resource and environmental footprints within China (Feng et al., 2013). The geographic scope of the 2012 MRIO table covers all the 31 provincial regions of Mainland China, excluding Hong Kong, Macau and Taiwan. According to the National Bureau of Statistics of China (NBSC, 2011), the 31 provincial-level regions can be conventionally divided into four areas, i.e., the Northeastern, Eastern, Central, and Western areas, as shown in Figure 1. Forty-two economic sectors in each region are included. Detailed sectoral and regional information is listed in Tables S3-4. 


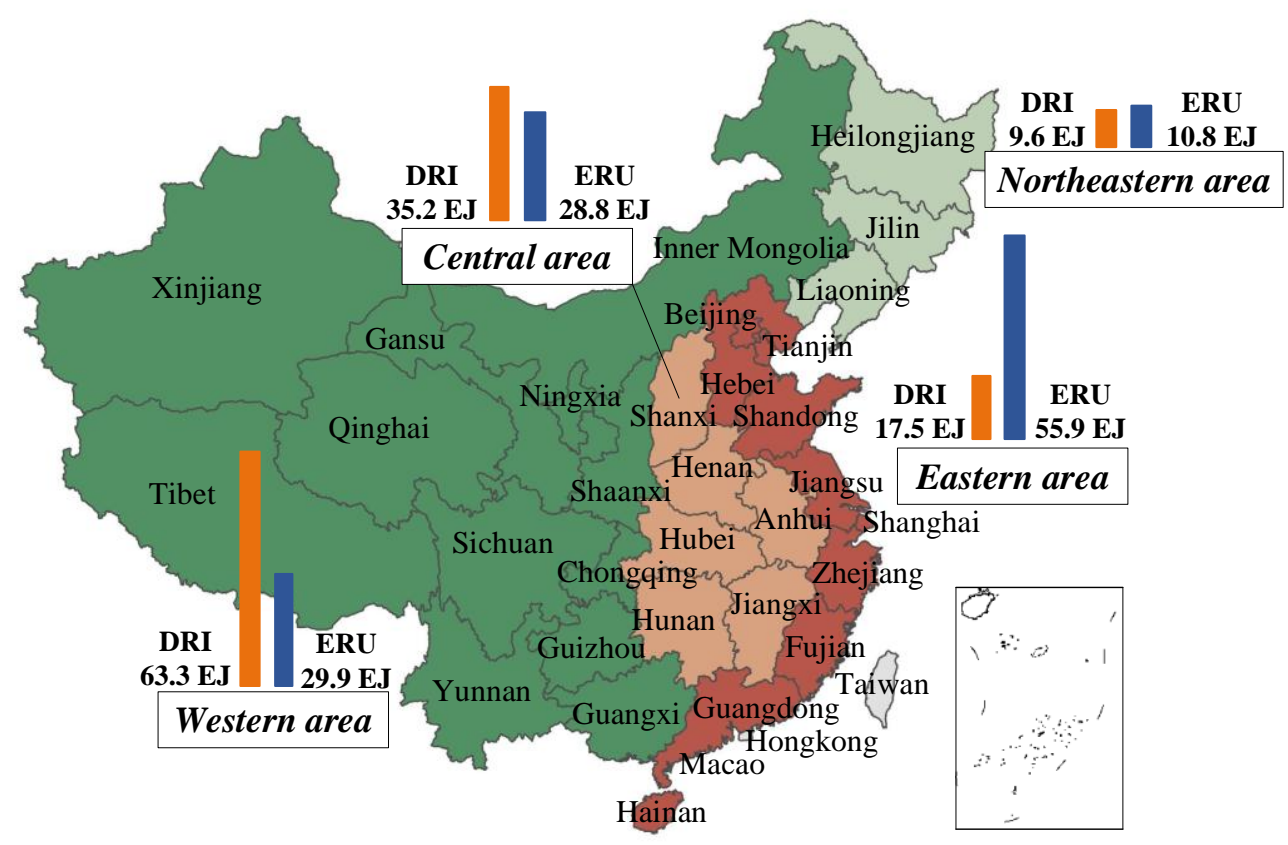

Fig. 1. Regional distribution of Mainland China.

Based on the non-competitive import assumption, the item of international import has been separated in the structure of the original MRIO table. As this study focuses on the domestic resource input within China, international imports are not considered in the EEIOA analysis. The basic row balance of the MRIO table can be expressed as (Zhang et al., 2015a, 2016),

$$
\begin{aligned}
& x_{i}^{f}=\sum_{s=1}^{31} \sum_{j=1}^{42} z_{i, j}^{f, s}+\sum_{s=1}^{31} \sum_{t=1}^{5} d_{i, t}^{f, s}+e_{i}^{f}+o_{i}^{f} \\
& =\sum_{s=1}^{31} \sum_{j=1}^{42} z_{i, j}^{f, s}+p_{i}^{f}
\end{aligned}
$$

where $x_{i}^{f}$ is the total output of Sector $i$ in Region $f ; z_{i, j}^{f, s}$ is the intermediate use of Sector $j$ in Region $s$ supplied by Sector $i$ in Region $f ; d_{i, t}^{f, s}$ represents the domestic final consumption of Region $s$ supplied by Sector $i$ in Region $f$, covering rural household consumption ( $t=1)$, urban household consumption $(t=2)$, government 
consumption (t=3), gross capital formation ( $t=4)$ and stock increase $(t=5) ; e_{i}^{f}$ is the exports from Sector $i$ in Region $f ; o_{i}^{f}$ is the other balance items of Sector $i$ in Region $f$; and $p_{i}^{f}$ is the total final use supplied by Sector $i$ in Region $f$.

The total resource balance of Sector $i$ in Region $f$ with Eq. (1) can be formulated as (Zhang et al., 2013, 2015a)

$$
\begin{aligned}
c_{i}^{f}+\sum_{s=1}^{31} \sum_{j=1}^{42} \varepsilon_{j}^{s} \times z_{j, i}^{f, s} & =\sum_{s=1}^{31} \sum_{j=1}^{42} \varepsilon_{i}^{f} \times z_{i, j}^{f, s}+\sum_{s=1}^{31} \sum_{t=1}^{5} \varepsilon_{i}^{f} \times d_{i, t}^{f, s}+\varepsilon_{i}^{f} \times e_{i}^{f}+\varepsilon_{i}^{f} \times o_{i}^{f} \\
& =\sum_{s=1}^{31} \sum_{j=1}^{42} \varepsilon_{i}^{f} \times z_{i, j}^{f, s}+\varepsilon_{i}^{f} \times p_{i}^{f}
\end{aligned}
$$

where $c_{i}^{f}$ is the direct resource exergy input (DRI) into Sector $i$ in Region $f ; \varepsilon_{j}^{s}$ is the embodied (direct plus indirect) resource exergy intensity of output from Sector $j$ in Region $s ; z_{j, i}^{f, s}$ denotes the intermediate input from Sector $j$ in Region $s$; and $\varepsilon_{i}^{f}$ represents the embodied resource exergy intensity of output from Sector $i$ in Region $f$.

For all sectors in the whole economy, the embodied resource exergy intensity matrix $E$ can be transformed into,

$$
E=C(X-Z)^{-1}
$$

The embodied resource exergy use (ERU) induced by specific final demand category can be calculated by multiplying embodied resource exergy use intensity matrix $E$ by the corresponding vector.

Referring to Sun et al. (2017) and Zhang et al. (2015a), the resource use embodied in interregional exports (ERIE) of Region 1 can be expressed as 


$$
\begin{aligned}
& \operatorname{ERIE}^{1}=C^{1}(X-Z)^{-1}\left(\sum_{s=2}^{31} \sum_{t=1}^{5} d_{t}^{s}+e^{s}+o^{s}\right) \\
& =\sum_{s=2}^{31} \operatorname{ERIT}^{1 S},(S \neq 1)
\end{aligned}
$$

where $C^{1}$ indicates the resource input from Region 1 (mainly referring to six extraction sectors); $d_{t}^{s}$ is the domestic final consumption of region $s ; e^{s}$ is the $31 \times 1$ column vector representing the exports of Region $s ; O^{s}$ is the $31 \times 1$ column vector representing the other balance items of Region $s$; and $E R I T^{1 S}$ is the transfer of embodied resource exergy flows from Region 1 to Region $s(s \neq 1)$. Thereafter, the DRI of Region 1 caused by the final demand in other provincial regions can be identified.

The resource use embodied in interregional imports (ERII) of Region 1 can also be calculated as

$$
E R I I^{1}=\sum_{s=2}^{31} E R I T^{s 1}
$$

where $E R I T^{s 1}$ is the transfer of embodied resource exergy flows from Region $s$ $(s \neq 1)$ to Region 1.

The net embodied resource use of interregional trade balance (ERIB=ERII-ERIE) can then be determined by the difference between ERII and ERIE. The regions with positive ERIB are identified as physical net importers in interregional trade, while those with negative ERIB are physical net exporters. It is worth noting that the ERIB of a region is also equal to the difference between its ERU and DRI (Zhang et al., 2013). Detailed procedures to calculating resource uses embodied in final demand and interregional trade can be referred to Zhang et al. (2015a) and Sun et al. (2017). 


\section{Results}

\subsection{Natural resource uses embodied in final demand}

The national total embodied resource use (ERU) amounted to 125.5 EJ in 2012. Energy minerals contributed the largest share of $84.1 \%$ (105.6 EJ). Agricultural resources and other primary energy accounted for $10.7 \%$ and $4.5 \%$ of the total ERU, respectively. Investment (including gross capital formation and stock increase) was the leading contributor to the total ERU, accounting for the largest amount of $66.4 \mathrm{EJ}$, followed by household consumption of $42.5 \mathrm{EJ}$ and export of $20.9 \mathrm{EJ}$.

Figure 2 shows the resource requirements driven by final demand of the 31 regions. The eastern area contributed the largest fraction of $44.5 \%$ to the total ERU, followed by the western area $(23.9 \%)$, the central area $(23.0 \%)$ and the northeastern area $(8.6 \%)$. The distribution of regional ERU from a consumption perspective was quite different from that of regional direct resource input (DRI) from a production perspective. The northeastern, eastern, central and western areas were responsible for $7.6 \%, 13.9 \%$, $28.0 \%$ and $50.4 \%$ of the national total DRI, respectively.

At the regional level, the eastern provincial regions generally had higher ERUs comparing to the western and central regions. The top 4 provinces with the largest ERUs were all from the eastern area: Jiangsu held the largest volume of $12.3 \mathrm{EJ}$, followed by Guangdong of 9.0 EJ, Zhejiang of 9.0 EJ and Shandong 8.7 EJ. In comparison, the ERUs of most eastern regions were much higher than the DRIs. Shanghai, Beijing, Hainan, Zhejiang and Fujian had small DRIs, less than 1.2 EJ. The 
ERUs of Shanghai, Beijing, and Zhejiang were 101.6, 12.6 and 11.7 times of their DRIs, respectively. Jiangsu and Guangdong had prominent ERUs which respectively were 8.4 and 4.3 times of the DRIs. Meanwhile, the ERUs of some central and western regions were much lower than their DRIs. For example, the ERUs of Inner Mongolia, Shaanxi, Shanxi, Ningxia and Guizhou were equal to only $17.6 \%, 25.3 \%$, $27.9 \%, 46.0 \%$ and $50.2 \%$ of their DRIs, respectively. Inner Mongolia had the largest regional DRI with an amount of 24.0 EJ (19.1\% of the total), but its ERU was only 4.2 EJ (3.4\% of the total). Similarly, the ERUs in Shanxi (5.7 EJ) and Shaanxi (3.4 EJ) were relatively low, in comparison with their huge DRIs of 20.5 and $13.5 \mathrm{EJ}$, respectively.

As to the ERU composition by final demand category (see Figure 2a), investment occupied a primary position in almost all regions, accounting for $40-80 \%$ of the ERUs in most regions, and particularly $95.9 \%$ in Shanxi, $80.1 \%$ in Shaanxi, and $73.1 \%$ in Ningxia. Consumption contributed $30 \%-50 \%$ of regional ERUs (e.g., $45.5 \%$ in Shaanxi and $45.4 \%$ in Heilongjiang). Some eastern coastal regions had prominent export-driven ERUs, due to their high degree of openness. For instance, export accounted for $42.3 \%, 35.8 \%, 32.1 \%$ and $32.0 \%$ of the ERUs in Shanghai, Guangdong, Jiangsu and Zhejiang, respectively. As to the resource category (see Figure 2b), energy minerals were the dominating resource type in all regions which contributed to about $70-90 \%$ of the regional ERUs, and particularly $92.4 \%$ for Shanghai, $92.4 \%$ for Shanxi and $90.5 \%$ for Shaanxi, respectively. The uses of fossil fuels played an important role in the regional economy. Detailed data are listed in Tables S5-6. 


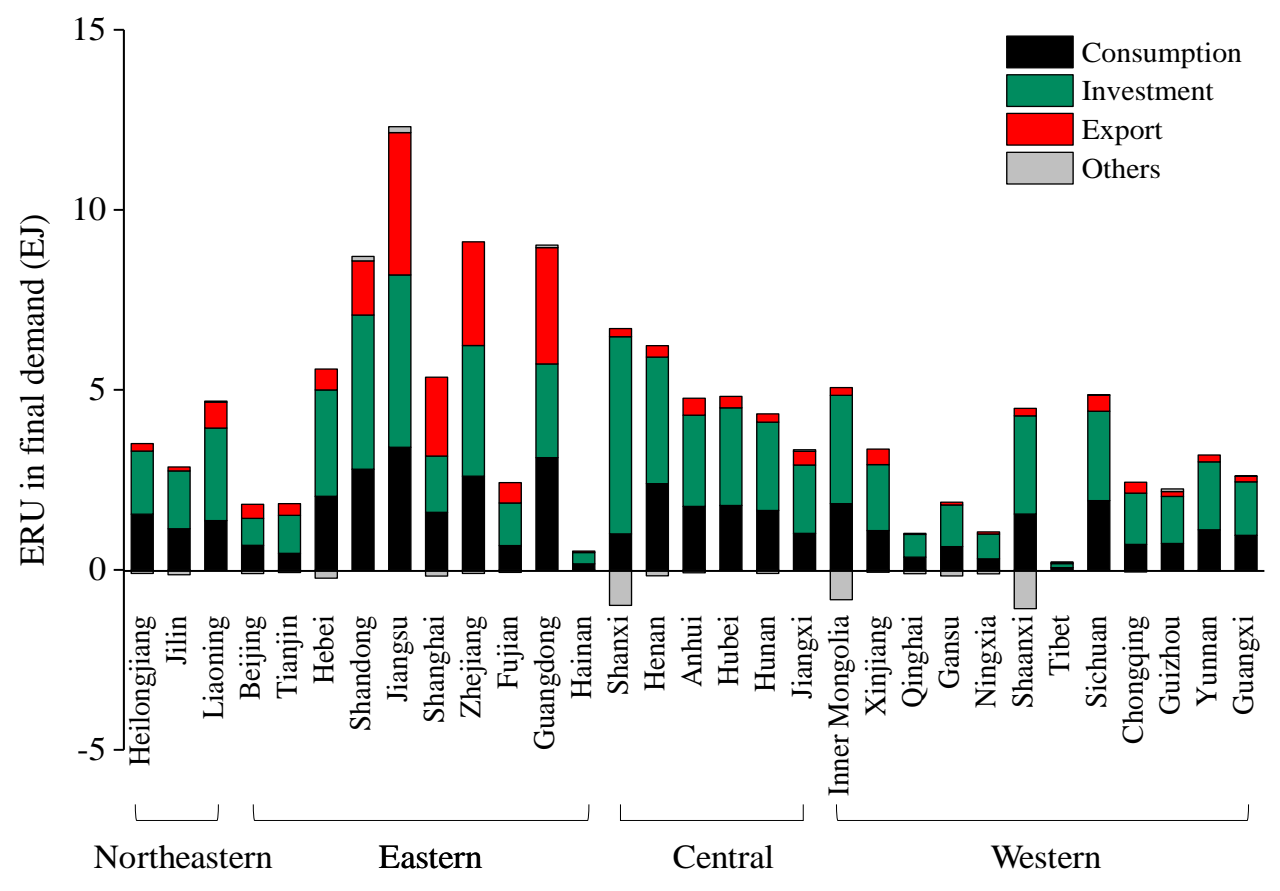

(a) By final demand category

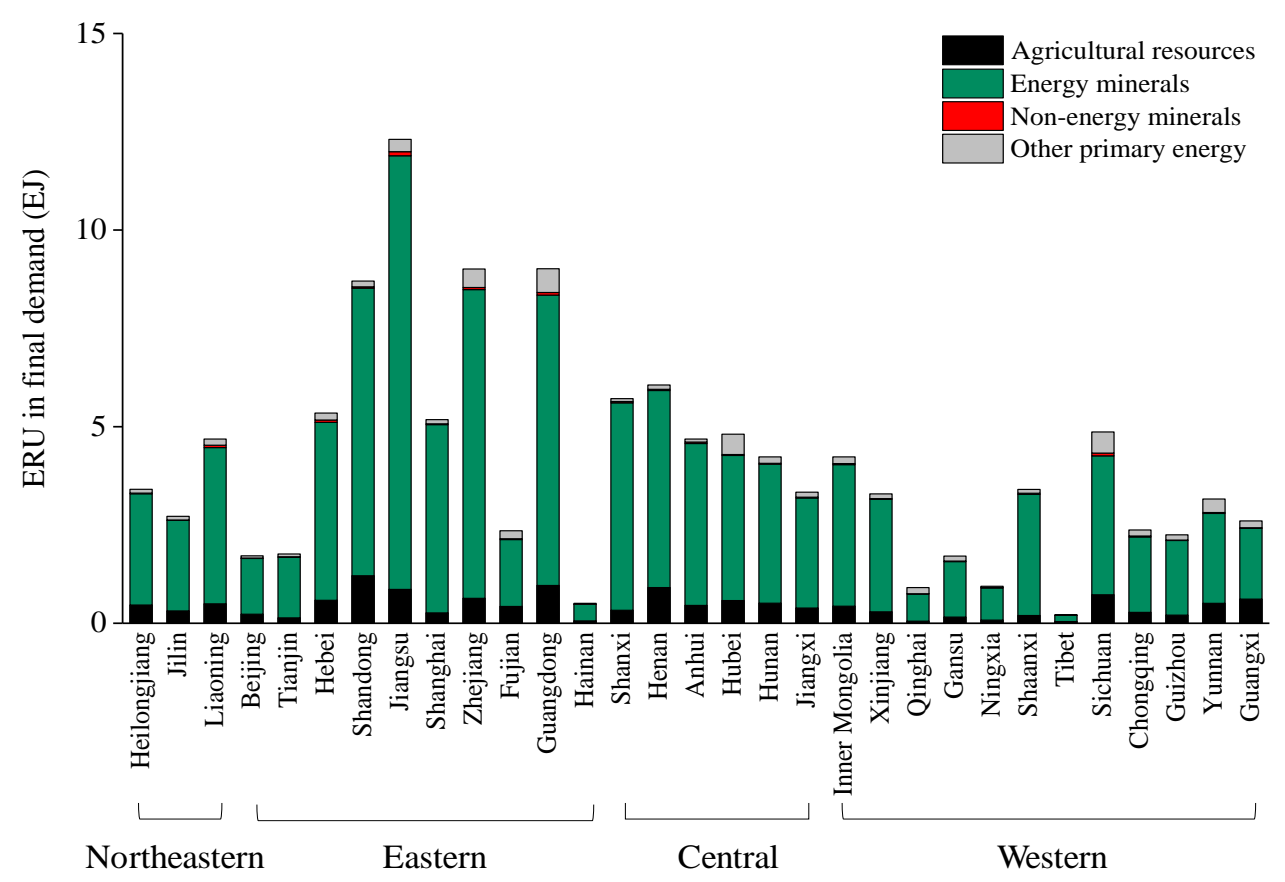

(b) By resource type

Fig. 2. Embodied resource uses (ERUs) in final demand by region. 


\subsection{Natural resource uses embodied in interregional trade}

The gross scale of interregional embodied resource transfer (total ERII or ERIE) was $87.3 \mathrm{EJ}$ in 2012 , being equal to $69.6 \%$ of the national direct resource input (DRI). Figure 3 presents the geographic distribution of the ERUs in interregional trade. As to the resource use embodied in interregional imports (ERII), the eastern area accounted for $53.7 \%$ of the total. Jiangsu and Zhejiang were the leading interregional importers, sharing $13.2 \%$ and $9.7 \%$ of the total ERII, respectively, followed by Guangdong ( $8.8 \%$ of the total), Shanghai $(5.9 \%)$ and Shandong $(5.8 \%)$. The aforementioned 5 regions, all located in the eastern coastal area, contributed to $43.4 \%$ of the total ERII. For the resource use embodied in interregional exports (ERIE), the largest interregional exporter was Inner Mongolia, sharing 24.4\% of the total, followed by Shanxi (20.8\%), Shaanxi (13.3\%), Xinjiang (4.6\%) and Heilongjiang (3.9\%). The western area contributed the largest share of $55.0 \%$ to the total ERIE, followed by the central area of $28.9 \%$, the eastern area of $9.6 \%$, and the northeastern area of $6.5 \%$.

The 31 provincial regions can be categorized into two groups according to the ERIB (the net embodied resource use of interregional trade balance) indicator. There were 22 provincial regions with physical net imports and other 9 regions with physical net exports. The western and central inland areas had the physical net exports of 33.3 EJ and 6.4 EJ, while the eastern and northeastern areas had the physical net imports of 38.5 EJ and 1.2 EJ, respectively. In the interregional net export group, Inner Mongolia was the largest net exporter, with the net trade volume of 19.7 EJ, followed by Shanxi (14.8 EJ), Shaanxi (10.1 EJ) and Xinjiang (2.9 EJ). In the interregional net import 
group, Jiangsu was the leading region with the largest net inflow of 10.8EJ. Zhejiang (8.2 EJ), Guangdong (6.9 EJ), and Shanghai (5.1 EJ) were the next three largest physical net importers. Detailed information about the geographic distributions of ERUs in interregional trade is listed in Table S7.

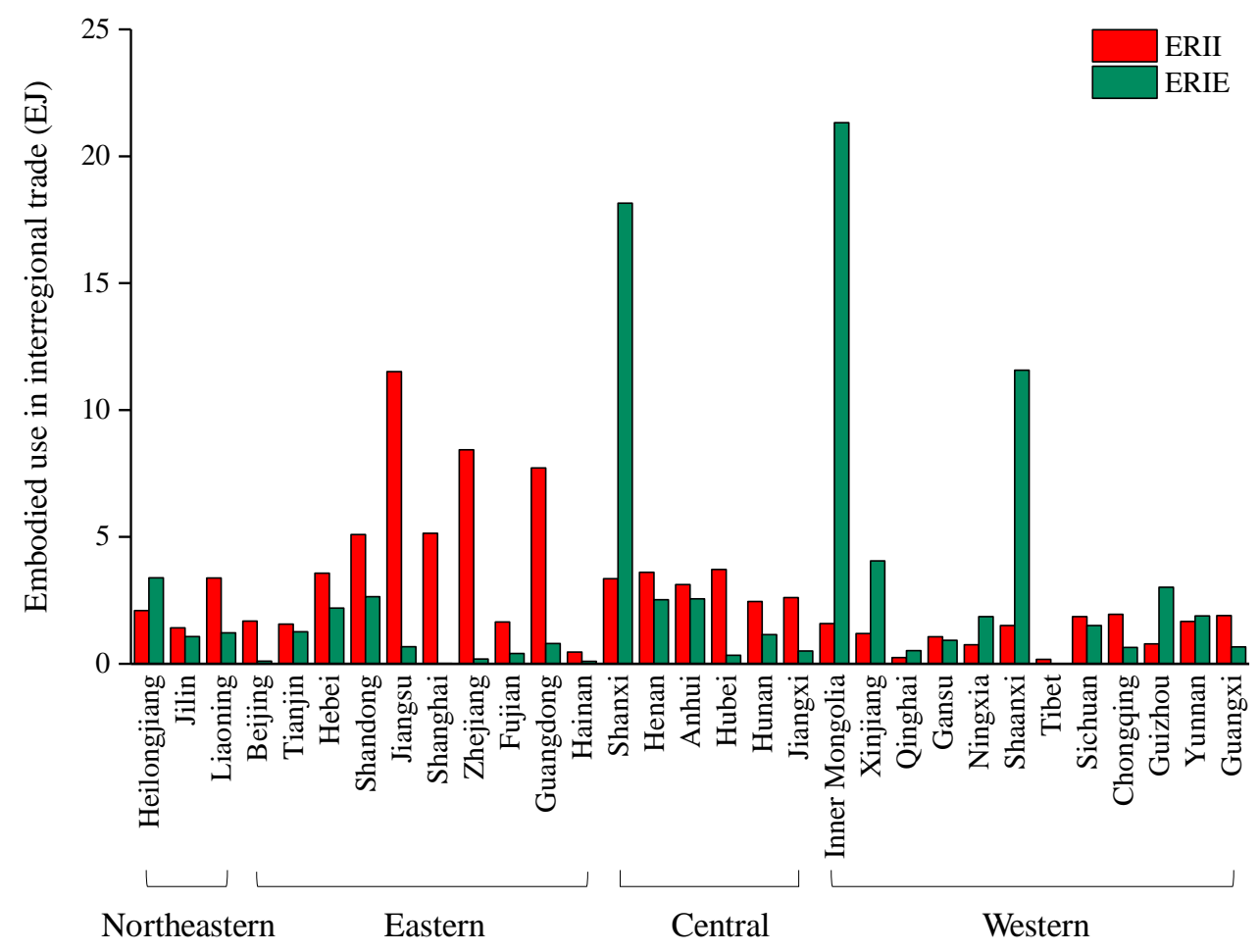

Fig. 3. Embodied resource uses (ERUs) in interregional trade by region.

Figure 4 further displays major interprovincial trade flows in terms of embodied resource transfer. Jiangsu, Zhejiang, Guangdong and Shanghai in the eastern area generated large amounts of outsourcing resource requirements, making up $37.6 \%$ of total interregional imports. Inner Mongolia, Shanxi and Shaanxi were the foremost resource suppliers, together accounting for $58.5 \%$ of the total ERIE. The top two trading flows were from Inner Mongolia and Shanxi to Jiangsu. Inner Mongolia's physical net export can be attributed to its extremely imbalanced resource (mainly 


\section{4 times its ERII.}

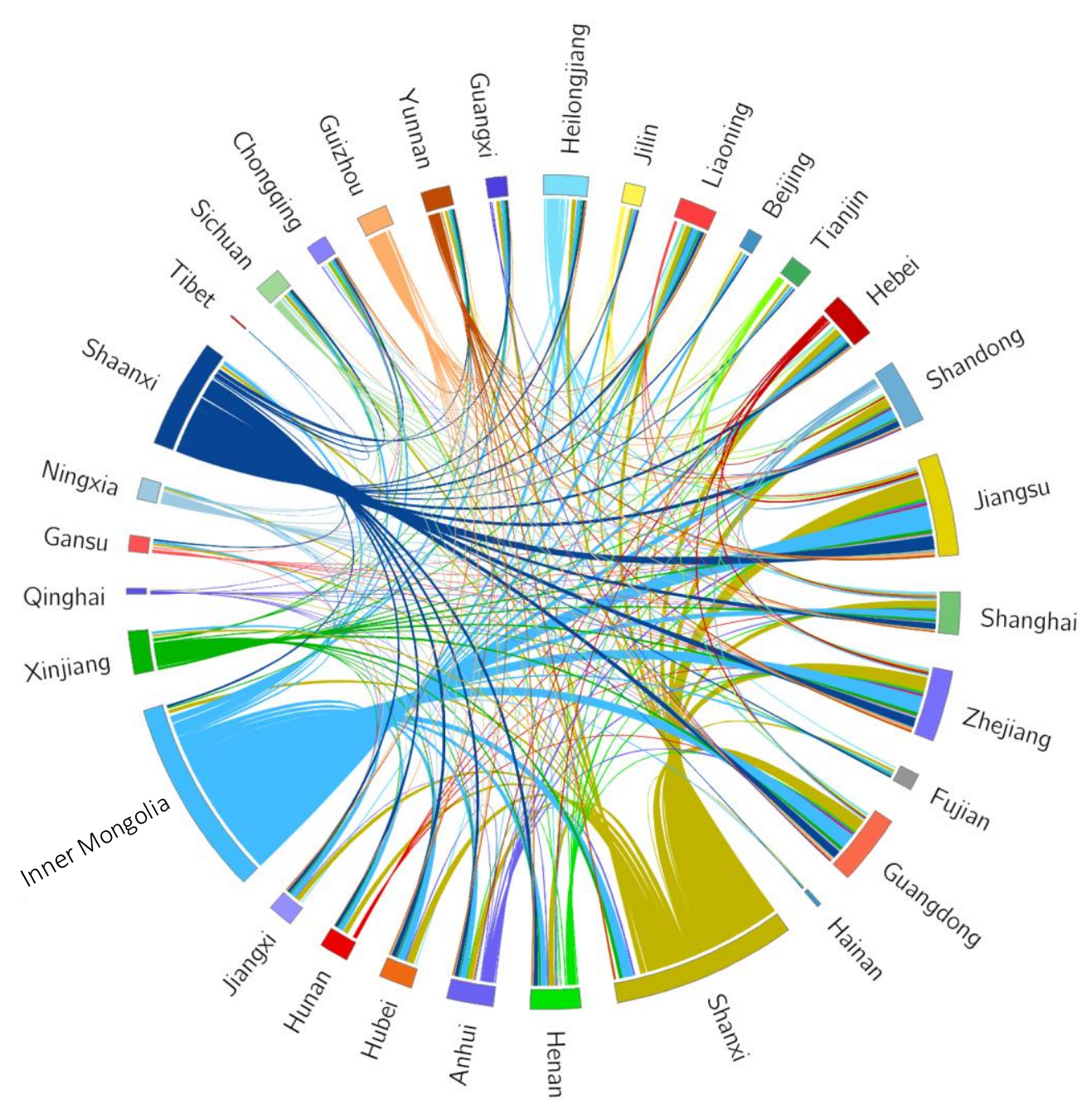

Fig. 4. Major embodied resource connections among 31 provincial regions. Note: The general trade relations between every two regions are portrayed by the chords. For each provincial region, the lines which have the same color with the outside arc stand for embodied resources in this region's export to other regions and the lines with other different colors stand for embodied resources in this region's import from other regions.

Figure 5 portrays the major physical fluxes via interregional net trade in terms of agricultural resources, energy minerals, non-energy minerals and other primary energy. 
The net transfer of embodied resources flowed mainly from the central and western areas to the eastern area, which suffered from physical net exports, while the main physical net importers were the developed coastal regions. $55.1 \%$ and $53.7 \%$ of the total ERIEs in the central area and the western area flowed into the eastern area, respectively. For the trading flows of agricultural resources (see Figure 5a), Guangxi, Heilongjiang, Anhui and Henan acted as major embodied resource suppliers, while Guangdong Zhejiang and Shandong played as embodied resource importers. For the energy minerals (see Figure 5b), the top 5 physical net exporters were Inner Mongolia (19.5 EJ), Shanxi (15.0 EJ), Shaanxi (10.1 EJ), Xinjiang (2.7 EJ) and Guizhou (2.1 EJ), while the top 5 physical net importers were Jiangsu (10.5 EJ), Zhejiang (7.8 EJ), Guangdong (6.5 EJ), Shanghai (4.8 EJ) and Hubei (3.5 EJ). Main resource transfers of embodied non-energy minerals flows were identified from Hebei to Jiangsu and Zhejiang (see Figure 5c). In addition, embodied resource flows of other primary energy (e.g., wind power and hydropower) are transferred from the western area to the eastern area, as displayed in Figure 5d. 


\subsection{Embodied natural resource uses by economic sector and industry}

To reveal resource information in the second and tertiary industries, Figure 6 shows the embodied resource uses (ERUs) by final demand category for all the 42 economic sectors. Construction (S28) held the top ERU in final demand, amounting to 36.7 EJ and accounting for $29.2 \%$ of the national total. Rapidly expanding infrastructure construction had a significant impact on resource uses, as construction activities need a great deal of direct and indirect resource inputs. Agriculture (S1), Food processing 
and tobaccos (S6), Transport equipment (S18) and Chemical industry (S12) also had significant sectoral ERUs, contributing to $6.6 \%, 6.0 \%, 5.5 \%$ and $4.7 \%$ of the national total, respectively. By contrast, the direct resource inputs (DRIs) were dominated by six resource extraction sectors (i.e., S1-5 and S25) such as Coal mining (S2, 73.4\% of the national total). It implies the complicated resource supply chain from production to consumption among various economic sectors.

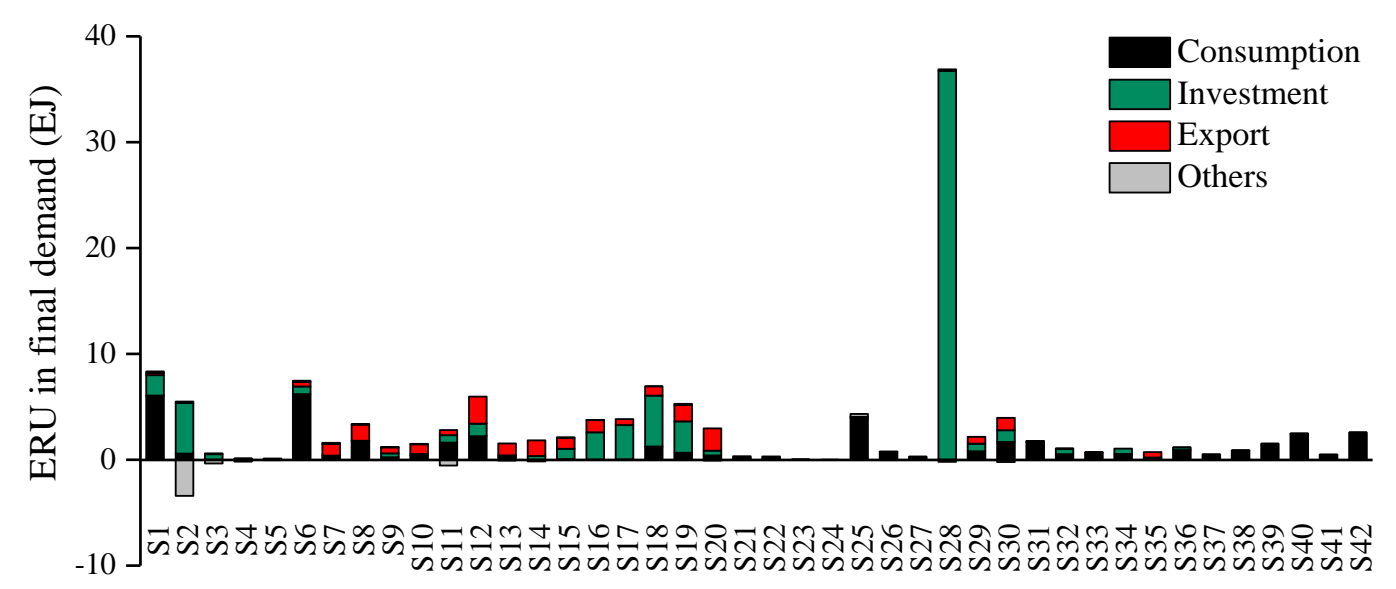

Fig. 6. Embodied resource uses (ERUs) in final demand by sector.

Investment into the second industry was a major driving factor of resource requirements. Sectors 28 (Construction), 18 (Transport equipment) and 2 (Coal mining) together contributed $69.8 \%$ of the total investment-driven ERU. Consumption was the leading final demand category for some industrial sectors related to people's daily expenditures, such as Agriculture (S1), Food processing and tobaccos (S6) and Electricity and hot water production and supply (S25). Some industrial sectors such as Sectors 7-20 had large ERUs in international exports, owing to China's massive 
exports of industrial raw materials, primary machinery and equipment products.

Figure 7 displays the sectoral composition of ERUs in final demand and interregional trade. All the 42 economic sectors were aggregated into 8 integrative categories, i.e., Agriculture, Mining, Light industry, Heavy industry, Power and heat, Construction, Transport, and Services (see Table S3). Heavy industry was the largest embodied resource user, followed by Construction, Services and Light industry. These four industry categories contributed to $84.2 \%$ and $84.9 \%$ of the total ERU in final demand and interregional trade, respectively. Figure 8 further displays the ERUs in interregional trade of 8 industry categories in the four areas. Heavy industry, Construction and Services together contributed to $73.7 \%$ of the total ERII of the eastern area. Heavy industry accounted for $33.1 \%$ of the total ERIE of the central area, followed by Construction (28.1\%) and Services (12.8\%). The 4 industry categories of Heavy industry, Construction, Services and Light industry together accounted for $84.3 \%$ of the total ERIE of the western area. Most industries of the eastern area were physical net importers. The situation was the opposite in the central and western areas. Therefore, the net transfers of embodied resources from the central and western areas to the eastern area can also be identified. 


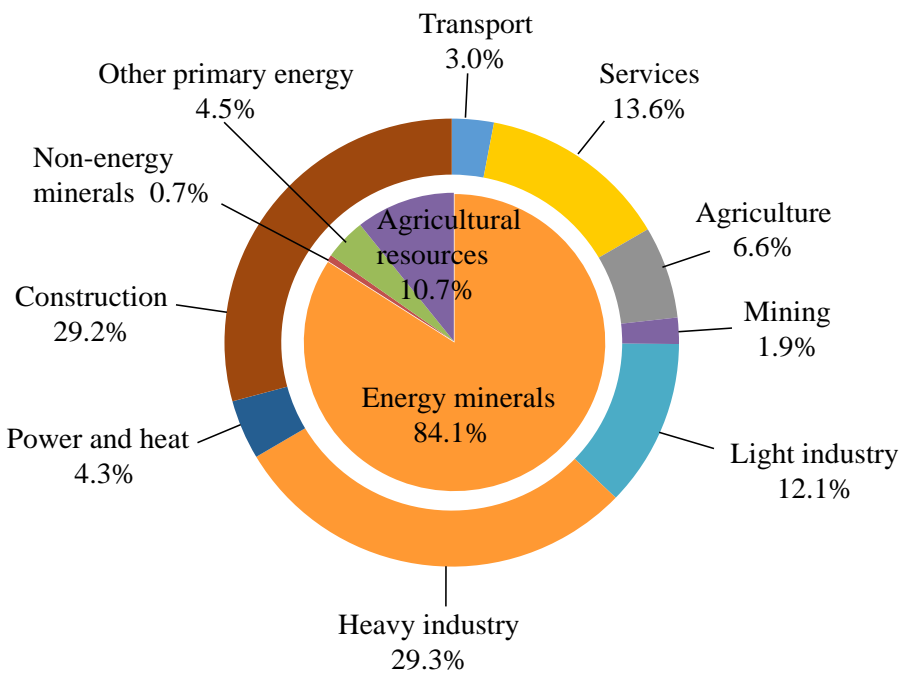

(a) ERUs in final demand.

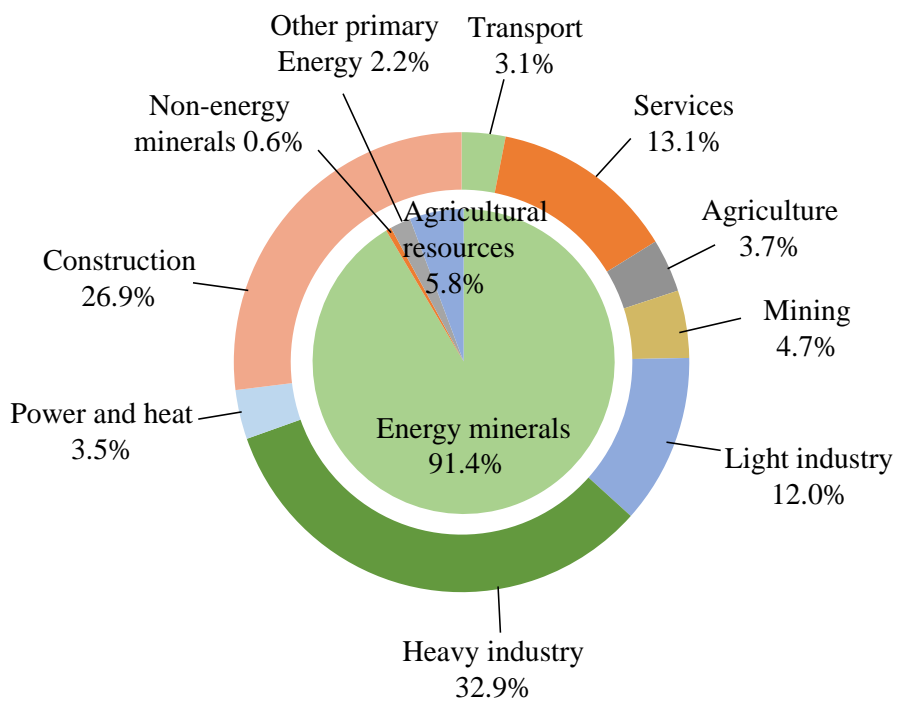

(b) ERUs in interregional trade.

Fig. 7. Compositions of embodied resource uses (ERUs) by resource category (Inner circle) and industry category (Outer circle). 

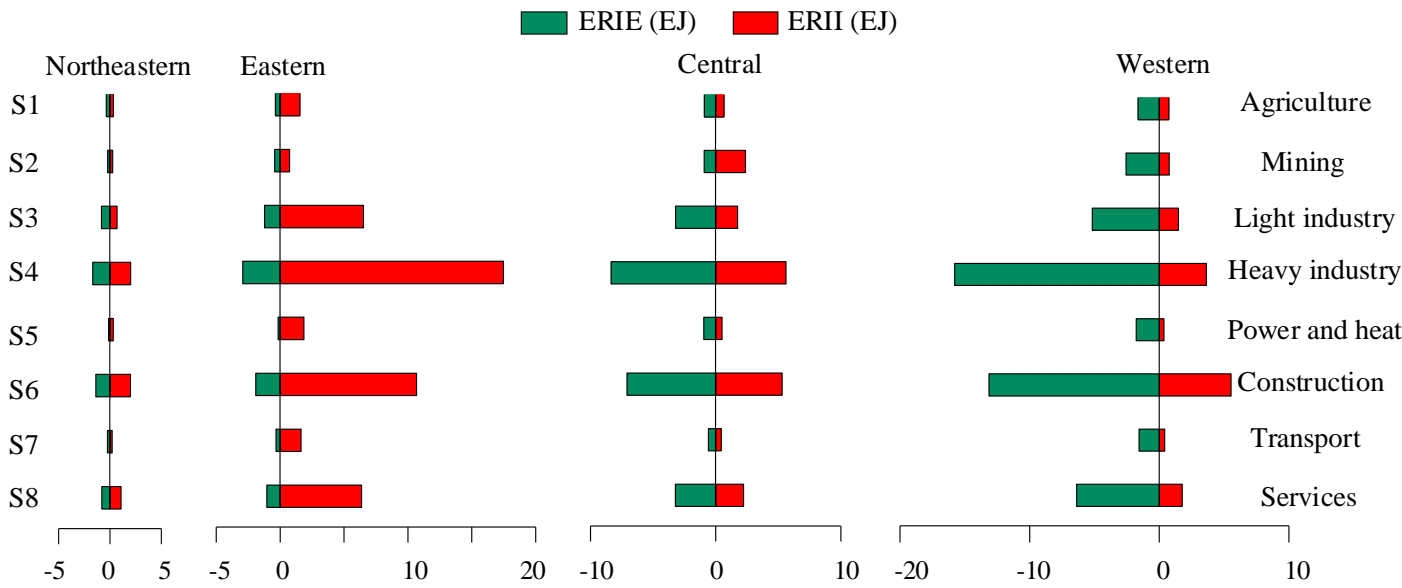

Fig. 8. Embodied resource uses (ERUs) in interregional trade of 8 industry categories in the four areas.

\section{Discussion}

Consumption demands are final drivers for the real natural resource requirements in a certain region. Economic development level, industrial structure and human lifestyle determine the patterns of regional embodied resource uses (ERUs). In 2012, the total GDP of the eastern area, covering China's three major economic circles, i.e., the Circum-Bohai Sea Economic Circle, the Yangtze Delta and the Pearl River Delta, was 5.9, 2.5 and 2.6 times of those of the northeastern, central and western areas, respectively. Figure 9 further presents the relationship between regional per capita gross domestic product (GDP) and per capita ERU (PERU). Owing to the uneven development within China, the regions with both higher total ERU and PERU were mainly in the developed regions with higher total GDP and per capita GDP. Such regions (e.g., Shanghai, Zhejiang and Jiangsu) also had larger per capita household consumption expenditures and consumption-driven PERUs (see Tables S4 and S8). Some western regions such as Inner Mongolia, Qinghai, Xinjiang and Ningxia had 
relatively high PERU values (especially investment-related PERU), due to their small population sizes. The ERU or per capita ERU can be used as an important indicator to reflect the resource and economic inequality among different provincial regions.

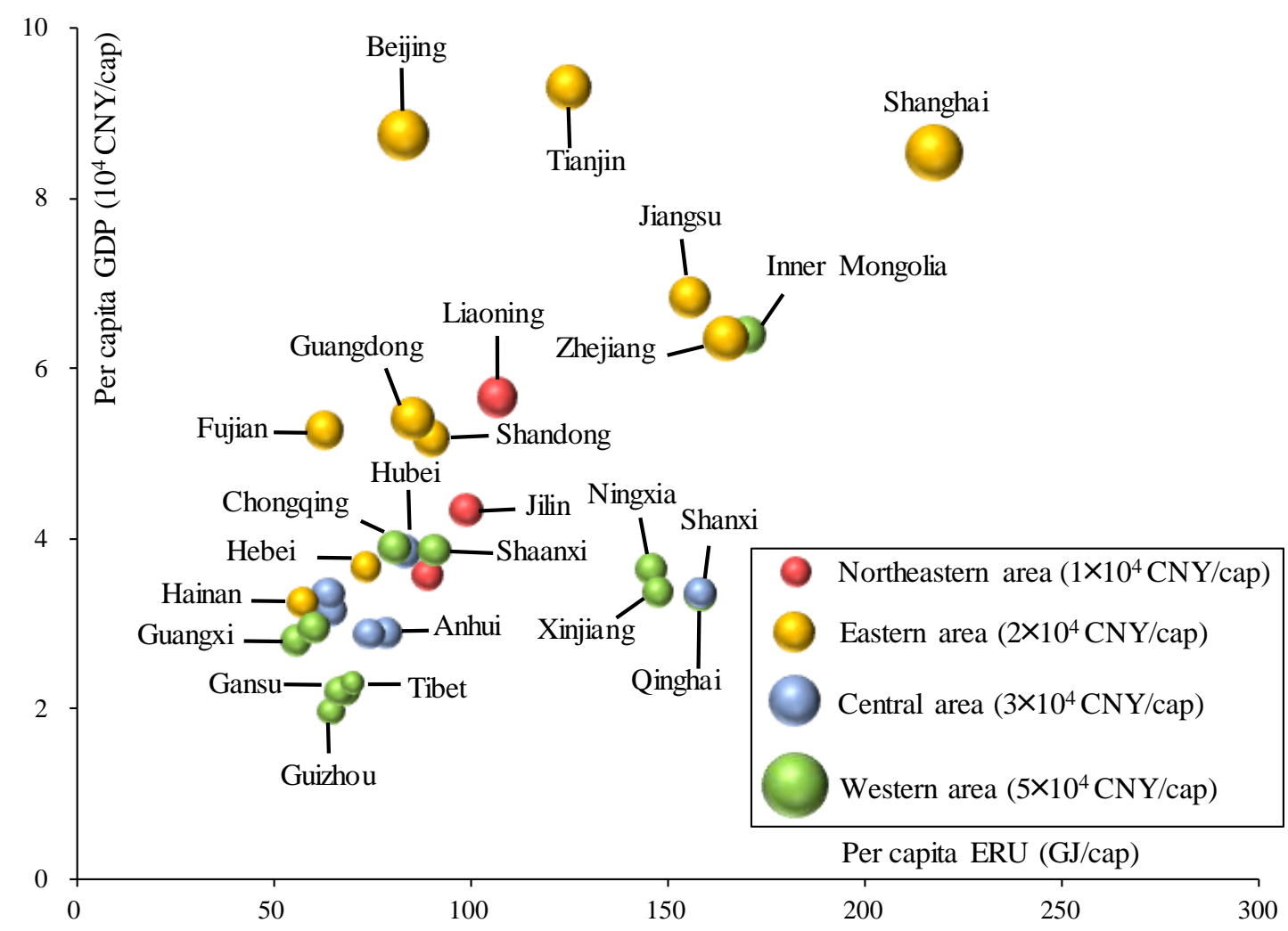

Fig. 9. The relationship between regional per capita GDP and per capita ERU. Note: The size of the sphere represents per capita household consumption expenditure.

The big difference between regional DRIs and ERUs confirms the significant role of interprovincial trade in reallocating resource requirements across China. Nearly $70 \%$ of the national total DRI in 2012 was directly or indirectly transferred via interprovincial trade. Figure 10 shows the trade imbalance in terms of economic and physical flows for 31 provincial regions. Central and western regions always suffered from physical net exports owing to their considerable resource exports as well as high 
resource intensities of interregional commodity exports. According to the comparative advantage theory, regions striving for a competitive advantage in the production or delivery of resource-intensive goods or services are more likely to be physical net exporters. In fact, China's natural resources are mainly distributed in the central and western areas. Inner Mongolia, Shanxi, Shaanxi and Xinjiang were main suppliers of coal and other energy minerals, providing natural resources to support the economic development of the eastern area. Meanwhile, the more developed eastern coast regions had larger resource demands but were less self-sufficient in natural resources. Material production and consumption activities in the eastern area of China were increasingly dependent on the supply of natural resources from other areas. As the largest physical net exporter, Inner Mongolia exported a lot of embodied resources, but obtained economic surplus in the interregional trade balance (see Table S9). However, Jiangsu as the largest physical net importer also gained economic surplus. Zhejiang, Guangdong and Shanghai were in the second quadrant, which obtained deficit in economic trade and imported embodied resources in production activities. The net transfers of embodied resource flows were from resource-rich and less-developed provinces to resource-poor and more developed regions, but the analysis of economic trade imbalance revealed the occurrence of ecologically unequal exchange among Chinese regions, as addressed by other related studies (e.g., Yu et al., 2014; Dorninger and Hornborg, 2015; Zhang et al., 2018c). 


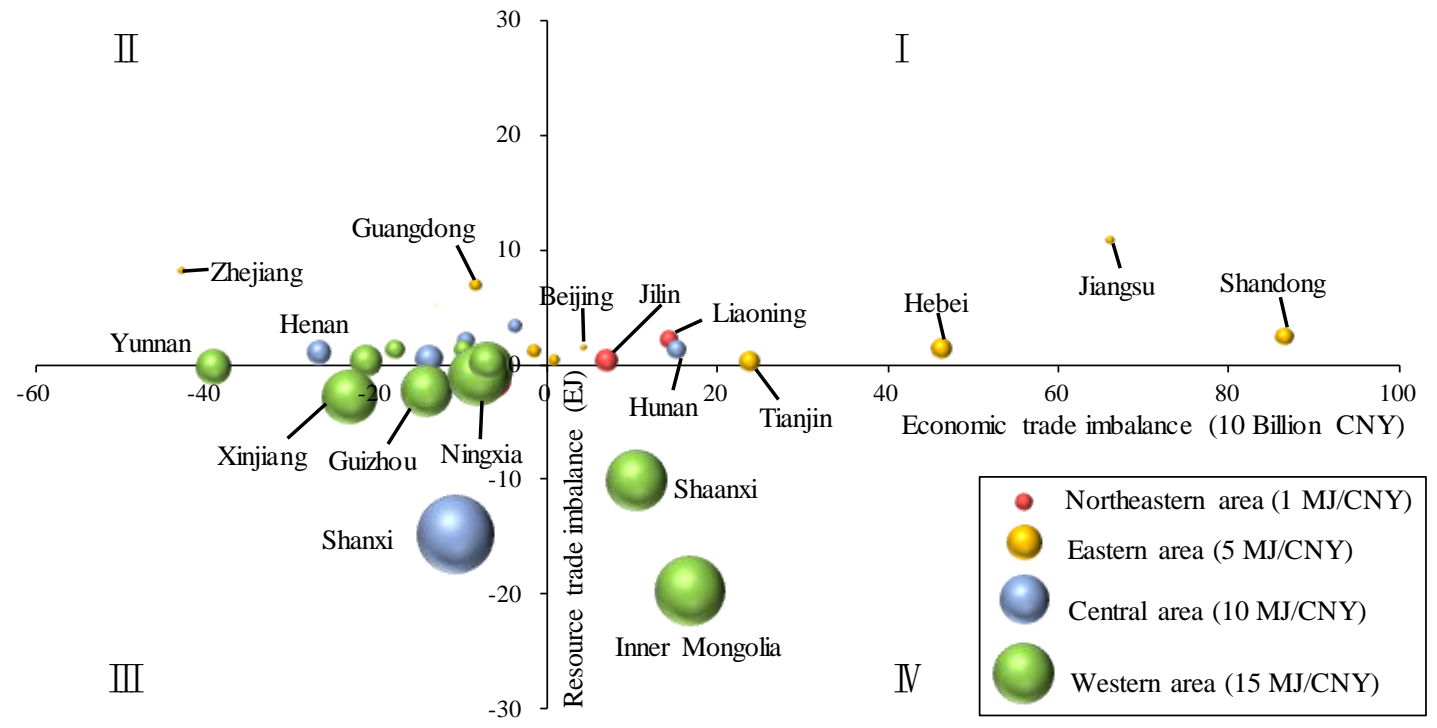

Fig. 10. Trade imbalance in terms of physical and economic flows by region. Note: The

interregional net trade volume is used to indicate the scale of region's trade imbalance. The four

quadrants in the rectangular coordinate represent four different trade patterns. Regions in the first

quadrant are physical net importers and monetary surplus receivers; regions in the second quadrant are physical net importers and monetary deficit receivers; regions in the third quadrant are physical net exporters and monetary deficit receivers; and regions in the fourth quadrant are physical net exporters and monetary surplus receivers. The size of the sphere represents the ratio of regional gross physical export to its monetary volume of export trade.

Irreversibility is intrinsic to any resource conversion process (Szargut, 1978; Sciubba, 2005). Exergy, representing available energy used to sustain the development of human society, is the "real resource" and "scarce resource" that is consumed or destroyed (Zhang et al., 2018a). Excessive exploitation and utilization of terrestrial exergy resources with no regard for environmental consequences has been regarded as the basic physical cause of resource and environmental issues (Chen, 
2005, 2006; Hermann, 2006). Many studies have addressed the resource challenges confronted with the Chinese society, due to large amounts of nonrenewable resource consumption and low resource use efficiencies (Wu et al., 2017; Zhang et al., 2018b). However, the pressures on the environment occur at various stages from resource production to final consumption along the whole supply chains. Consumption-based accounting in terms of embodied exergy identifies the resource utilization pattern in a macro-level accounting system, which could serve as the basis for assessing all possible paths to promote resource utilization level of a socioeconomic system. More importantly, the saving of "embodied resources" enables policy makers to require the consumers and other stakeholders bearing a part in more sustainable resource uses.

After addressing interprovincial economic linkages and related resource connections via the MRIO modeling, the downstream and upstream responsibilities of resource requirements for sectors and regions can be reallocated quantitatively. Regional resource uses induced by investment, consumption and international exports raise the attention to better formulating interprovincial coordinated policies for supply chain management. The western and central regions of China with lower technology and management skill levels are more vulnerable to the overexploitation of resources and ecological damages. In view of the fact that ecological debts that are not being properly compensated in trade exchange, resource depletion and environmental burden shifts can influence a region's comparative advantage. However, underdeveloped areas are always concerned with the economic benefits of their exports but ignore the occurrence of ecologically unequal exchange in the 
commodities that are traded between regions. These regions should give full considerations to the trade-off between economic gains and resource losses induced by interprovincial trade. Meanwhile, eastern developed regions such as Jiangsu, Zhejiang, Guangdong, Shanghai and Shandong should take the lead on the demand-side resource management such as increasing the efficiency of material production and consumption, improving coal-dominated energy structure, and optimizing the industrial structures to conserve resources and mitigate environmental burdens (Zhang et al., 2013). The developed regions as major physical net importers also have an obligation to narrow the interprovincial technical gaps and to aid the underdeveloped regions by investing in technology transfer, regional joint funds of ecological compensation and other practices.

\section{Concluding remarks}

With continued economic growth and accelerated urbanization and industrialization, China will rely on more natural resources to meet domestic consumption and trade demands. Decoupling economic growth from natural resource use has been listed as an important aspect of Goal 12 (Ensure sustainable consumption and production patterns) in the sustainable development goals (SDGs) set by the United Nations. Ensuring the sustainability of the Chinese society requires the effective use of resources to minimize environmental impacts at different scales. Integrated approaches or indicators such as embodied resource requirements or resource 
footprints should be developed for establishing sound resource and environmental policies (Tian et al., 2017; Zhang et al., 2018a). Exergy based on the first and second laws of thermodynamics raises a unified metric for evaluating the various types of natural resource. Consumption-based resource exergy accounting does not record the actual physical movement of materials, but instead enumerates the overall resource linkages associated with production, consumption and trade. This study describes how final demand and interregional trade affects regional resource uses and provides a different insight for optimizing material footprints. Since 2012, China has entered a new phase of economic development $-\mathrm{a}$ 'new normal'. Examining the outsourcing of resource requirements within China for a benchmark year provides solid foundation for understanding the structure and spatial distribution of resource inventories under different phases of regional economic development and establishing effective regulatory strategies of production, trade and consumption activities to accelerate a shift towards sustainability.

\section{Acknowledgements}

This study has been supported by the National Natural Science Foundation of China (Grant nos. 71774161 and 71403270), the National Key Research and Development Program of China (Grant no. 2017YFB0601900) and the Yue Qi Young Scholar Project, China University of Mining \&Technology (Beijing). Very helpful comments by the anonymous reviewers and the editor are highly appreciated. 


\section{Appendix A. Supplementary data}

Supplementary data associated with this article can be found in the online version.

\section{References}

An, Q., An, H., Wang, L., Huang, X., 2014. Structural and regional variations of natural resource production in China based on exergy. Energy 74, 67-77.

An, Q., An, H., Wang, L., Gao, X., Lv, N., 2015. Analysis of embodied exergy flow between Chinese industries based on network theory. Ecological Modelling318, 26-35.

Ayres, R.U., Ayres, L.W., Warr, B., 2003. Exergy, power and work in the US economy, 1900-1998. Energy 28(3), 219-273.

Brockway, P.E., Steinberger, J.K., Barrett, J.R., Foxon, T.J., 2015. Understanding China's past and future energy demand: An exergy efficiency and decomposition analysis. Applied Energy155, 892-903.

CAIY, 2013. China Animal Industry Yearbook 2013. China Statistics Press, Beijing.

CASY, 2013. China Agricultural Statistical Yearbook 2013.China Statistics Press, Beijing.

CEPY, 2013. China Electric Power Yearbook 2013. China Statistics Press, Beijing.

CESY, 2014. China Energy Statistical Yearbook 2013. China Statistics Press, Beijing.

CFSY, 2013. China Forestry Statistical Yearbook 2013.China Statistics Press, Beijing.

Chen, B., Chen, G.Q., 2006. Exergy analysis for resource conversion of the China Society 1993 under the Material product system. Energy 31(8-9), 1115-1150.

Chen, B., Chen, G.Q., 2007a. Modified ecological footprint accounting and analysis based on embodied exergy — a case study of the Chinese society 1981-2001. Ecological Economics 61(2-3), 
Chen, B., Chen, G.Q., Yang, Z.F., 2006. Exergy-based resource accounting for China. Ecological Modelling 196(3-4), 313-328.

Chen, G.Q., 2005. Exergy consumption of the earth. Ecological Modelling 184(2-4), 363-380.

Chen, G.Q., 2006. Scarcity of exergy and ecological evaluation based on embodied exergy. Communications in Nonlinear Science and Numerical Simulation 11(4), 531-552.

Chen, G.Q., Chen, B., 2007b. Resource analysis of the China Society 1980-2002 based on exergy—Part 5: Resource structure and intensity. Energy Policy 35(4), 2087-2095.

Chen, G.Q., Chen, B., 2007c. Resource analysis of the China Society 1980-2002 based on exergy—Part 1: Fossil fuels and energy minerals. Energy Policy 35(4), 2038-2050.

Chen, G.Q., Chen, Z.M., 2010. Carbon emissions and resources use by Chinese economy 2007: A 135-sector inventory and input-output embodiment. Communications in Nonlinear Science and Numerical Simulation 15(11), 2647-2732.

Chen, G.Q., Chen, Z.M., 2011. Greenhouse gas emissions and natural resources use by the world economy: Ecological input-output modeling. Ecological Modelling 222(14), 2362-2376.

CISY, 2013. China Industry Statistical Yearbook 2013. China Statistics Press, Beijing.

CMY, 2013. China Mining Yearbook 2013. China Statistics Press, Beijing.

CNMY, 2013. China Nonferrous Metal Yearbook 2013. China Statistics Press, Beijing.

Dewulf, J., Langenhove, H.V., Muys, B., Bruers, S., Bakshi, B.R., Grubb, G.F., Paulus, D.M., Sciubba, E., 2008. Exergy: its potential and limitations in environmental science and technology. Environmental Science and Technology 42(7), 2221-2232.

Dorninger, C., Hornborg, A., 2015. Can EEMRIO analyses establish the occurrence of ecologically 
unequal exchange? Ecological Economics 119, 414-418.

Feng, K., Davis, S.J., Sun, L.X., Li, X., Guan, D.B., Liu, W.D., Liu, Z., Hubacek, K., 2013. Outsourcing $\mathrm{CO}_{2}$ within China. Proc. Natl. Acad. Sci. USA 110(28), 11654-11659.

Feng, K., Siu, Y.L., Guan, D., Hubacek, K., 2012. Analyzing drivers of regional carbon dioxide emissions for China. Journal of Industrial Ecology 16(4), 600-611.

Hawkins, J., Ma, C., Schilizzi, S., Zhang, F., 2015. Promises and pitfalls in environmentally extended input-output analysis for China: A survey of the literature. Energy Economics 48, 81-88.

Hermann, W.A., 2006. Quantifying global exergy resources. Energy 31(12), 1349-1366.

Liang, Q.M., Fan, Y., Wei, Y.M., 2007. Multi-regional input-output model for regional energy requirements and $\mathrm{CO}_{2}$ emissions in China. Energy Policy 35(3), 1685-1700.

Liang, S., Zhang, C., Wang, Y., Xu, M., Liu, W., 2014. Virtual atmospheric mercury emission network in China. Environmental Science and Technology 48 (5), 2807-2815

Liang, S., Wang, Y., Zhang, C., Xu, M., Yang, Z., Liu, W., Liu, H., Chiu, A.S.F., 2017. Final production-based emissions of regions in China. Economic Systems Research 30(1), 18-36.

Liu, L.C., Liang, Q.M., Wang, Q., 2015. Accounting for China’s regional carbon emissions in 2002 and 2007: production-based versus consumption-based principles. Journal of Cleaner Production 103, 384-392.

Liu, Q., Wang, Q., 2017. Sources and flows of China's virtual $\mathrm{SO}_{2}$ emission transfers embodied in interprovincial trade: A multiregional input-output analysis. Journal of Cleaner Production 161, 735-747.

Liu, W.D., Tang, Z.P., Han, M.Y., et al., 2018. The 2012 China multi-regional input-output table of 31 provincial units. Beijing: China Statistics Press. 
Liu, Z., Guan, D., Wei, W., Davis, S.J., Ciais, P., Bai, J., et al., 2015. Reduced carbon emission estimates from fossil fuel combustion and cement production in China. Nature 524, 335-338.

Meng, B., Xue, J.J., Feng, K.S., 2013. China's inter-regional spillover of carbon emissions and domestic supply chains. Energy Policy 61, 1305-1321.

Mi, Z., Meng, J., Guan, D., Shan, Y., Song, M., Wei, Y.M., Liu, Z., Hubacek, K., 2017. Chinese $\mathrm{CO}_{2}$ emission flows have reversed since the global financial crisis. Nature Communications 8(1), 1712. doi:10.1038/s41467-017-01820-w.

NBSC, National Bureau of Statistics of China, 2011. The division method of the Eastern, Western, Central and Northeastern areas in China (in Chinese). Also available at: http://www.stats.gov.cn/ztjc/zthd/sjtjr/dejtjkfr/tjkp/201106/t20110613_71947.htm.

NBSC, National Bureau of Statistics of China, 2013. China Statistical Yearbook 2013. Also available at: http://www.stats.gov.cn/tjsj/ndsj/2013.

NBSC, National Bureau of Statistics of China, 2016. China Statistical Yearbook 2016. Also available at: http://www.stats.gov.cn/tjsj/ndsj/2016.

Sciubba, E., 2005. Exergo-economics: thermodynamic foundation for a more rational resource use. International Journal of Energy Research 29(7), 613-636.

Sciubba, E., Bastianoni, S., 2008 Exergy and extended exergy accounting of very large complex systems with an application to the province of Siena, Italy. Journal of Environmental Management 86(2), 372-382.

Shao, L., Li, Y., Feng, K.S., Meng, J., Shan, Y.L., Guan, D.B., 2018. Carbon emission imbalances and the structural paths of Chinese regions. Applied Energy215, 396-404.

Shao, L., Wu, Z., Chen, G.Q., 2013. Exergy based ecological footprint accounting for China. 
Ecological Modelling 252, 83-96.

Su, B., Ang, B.W., 2014. Input-output analysis of $\mathrm{CO}_{2}$ emissions embodied in trade: A multi-region model for China. Applied Energy 114, 377-384.

Sun, X.D., Li, J.S., Qiao, H., Zhang, B., 2017. Energy implications of China's regional development: New insights from multi-regional input-output analysis. Applied Energy 196, 118-131.

Szargut, J., 1978. Minimization of the consumption of natural resources. Bulletin of the Polish Academy of Sciences: Technical Sciences 26, 41-46.

Szargut, J., 2005. Exergy method: Technical and ecological applications. Southampton: WIT Press, Country Southampton.

Tian, X., Wu, R., Geng, Y., Bleischwitz, R., Chen, Y., 2017. Environmental and resources footprints between China and EU countries. Journal of Cleaner Production 168, 322-330

Ukidwe, N.U., Bakshi, B.R., 2004. Thermodynamic accounting of ecosystem contribution to economic sectors with application to 1992 US economy. Environmental Science and Technology 38, 4810-4827.

Ukidwe, N.U., Bakshi, B.R., 2007. Industrial and ecological cumulative exergy consumption of the United States via the 1997 input-output benchmark model. Energy 32(9), 1560-1592.

Valero, A., Valero, A., Calvo, G., 2015. Using thermodynamics to improve the resource efficiency indicator GDP/DMC. Resources, Conservation and Recycling 94, 110-117.

Wall, G., 1977. Exergy - a useful concept within resource accounting. Report no.77-42.Institute of Theoretical Physics, Gőteborg, Sweden.

Wang, F., Liu, B., Zhang, B., 2017. Embodied environmental damage in interregional trade: a MRIO-based assessment within China. Journal of Cleaner Production 140, 1236-1246. 
Wang, J., Li, L., Li, F., Kharrazi, A., Bai, Y., 2018. Regional footprints and interregional interactions of chemical oxygen demand discharges in China. Resources, Conservation and Recycling 132, 386-397.

Wang, Z., Xiao, C., Niu, B., Deng, L., Liu, Y., 2017. Identify sectors' role on the embedded $\mathrm{CO}_{2}$ transfer networks through China's regional trade. Ecological Indicators 80, 114-123.

Warr, B., Ayres, R.U., 2012. Useful work and information as drivers of economic growth. Ecological Economics 73, 93-102.

Wiedmann, T., 2009. A review of recent multi-region input-output models used for consumption-based emission and resource accounting. Ecological Economics 69(2), 211-222.

Wu, R., Geng, Y., Liu, W., 2017. Trends of natural resource footprints in the BRIC (Brazil, Russia, India and China) countries. Journal of Cleaner Production 142, Part 2, 775-782.

Yang, X., Zhang, W., Fan, J., Yu, J., Zhao, H., 2018. Transfers of embodied $\mathrm{PM}_{2.5}$ emissions from and to the North China region based on a multiregional input-output model. Environmental Pollution 235, 381-393.

Yu, Y., Feng, K., Hubacek, K., 2014. China’s unequal ecological exchange. Ecological Indicators 47, 156-163.

Zhang, B., Chen, G.Q., 2010. Physical sustainability assessment for the China society: exergy-based systems account for resources use and environmental emissions. Renewable and Sustainable Energy Reviews 14(6), 1527-1545.

Zhang, B., Chen, Z.M., Xia, X.H., Xu, X.Y., Chen, Y.B., 2013. The impact of domestic trade on China's regional energy uses: a multi-regional input-output modeling. Energy Policy 63, 1169-1181. Zhang, B., Guan, S.H., Wu, X.F., Zhao, X., 2018a. Tracing natural resource uses via China's supply 
chains. Journal of Cleaner Production 196, 880-888.

Zhang, B., Meng, Z., Zhang, L., Sun, X., Hayat, T., Alsaedi, A., Hayat, T., Ahmad, B., 2018 b. Exergy-based systems account of national resource utilization: China 2012. Resources, Conservation and Recycling 132, 324-338.

Zhang, B., Qiao, H., Chen, B., 2015a. Embodied energy uses by China's four municipalities: a study based on multi-regional input-output model. Ecological Modelling 318, 138-149.

Zhang, B., Qiao, H., Chen, Z.M., Chen, B., 2016. Growth in embodied energy transfers via China's domestic trade: Evidence from multi-regional input-output analysis. Applied Energy 184, 1093-1105.

Zhang, C., Anadon, L. D., 2014. A multi-regional input-output analysis of domestic virtual water trade and provincial water footprint in China. Ecological Economics 100, 159-172.

Zhang, H., Lahr, M.L., 2014. China's energy consumption change from 1987 to 2007: A multi-regional structural decomposition analysis. Energy Policy 67, 682-693.

Zhang, L.X., Hao, Y., Chang, Y., Pang, M.Y., Tang, S.J., 2017. Emergy based resource intensities of industry sectors in China. Journal of Cleaner Production 142(2), 829-836.

Zhang, W., Liu, Y., Feng, K., Hubacek, K., Wang, J., Liu, M., Jiang, L., Jiang, H., Liu, N., Zhang, P., Zhou, Y., Bi, J., 2018c. Revealing environmental inequality hidden in China's inter-regional trade. Environmental Science \& Technology 52 (13), 7171-7181.

Zhang, Y., Wang, H., Liang, S., Xu, M., Liu, W., Li, S., Zhang, R., Nielsen, C.P., Bi, J., $2014 a$. Temporal and spatial variations in consumption-based carbon dioxide emissions in China. Renewable and Sustainable Energy Reviews 40, 60-68.

Zhang, Y., Zheng, H., Yang, Z., Su, M., Liu, G., Li, Y., 2015b. Multi-regional input-output model and 
ecological network analysis for regional embodied energy accounting in China. Energy Policy 86, 651-663.

Zhang, Z., Guo, J., Hewings, G.J.D., 2014b. The effects of direct trade within China on regional and national $\mathrm{CO}_{2}$ emissions. Energy Economics 46, 161-175.

Zhou, X., Imura, H., 2011. How does consumer behavior influence regional ecological footprints? An empirical analysis for Chinese regions based on the multi-region input-output model. Ecological Economics $71(1), 171-179$. 


\section{Figure captions}

Fig. 1. Regional distribution of Mainland China.

Fig. 2. Embodied resource uses (ERUs) in final demand by region.

Fig. 3. Embodied resource uses (ERUs) in interregional trade by region.

Fig. 4. Major embodied resource connections among 31 provincial regions.

Fig. 5. Major embodied resources fluxes of net interregional trade.

Fig. 6. Embodied resource uses (ERUs) in final demand by sector.

Fig. 7. Compositions of embodied resource uses (ERUs) by resource category (Inner circle) and industry category (Outer circle).

Fig. 8. Embodied resource uses (ERUs) in interregional trade of 8 industry categories in the four areas.

Fig. 9. The relationship between regional per capita GDP and per capita ERU.

Fig. 10. Trade imbalance in terms of physical and economic flows by region. 


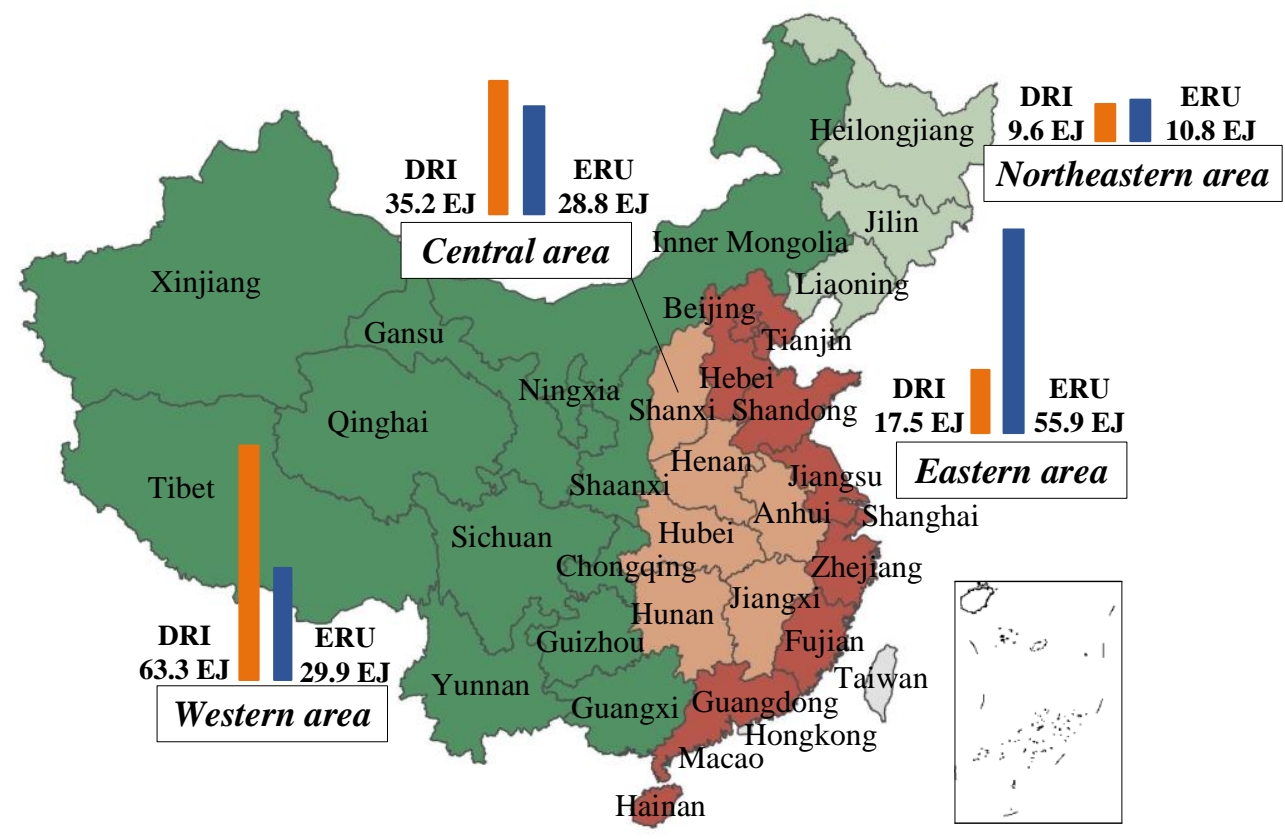

Fig. 1. Regional distribution of Mainland China. 


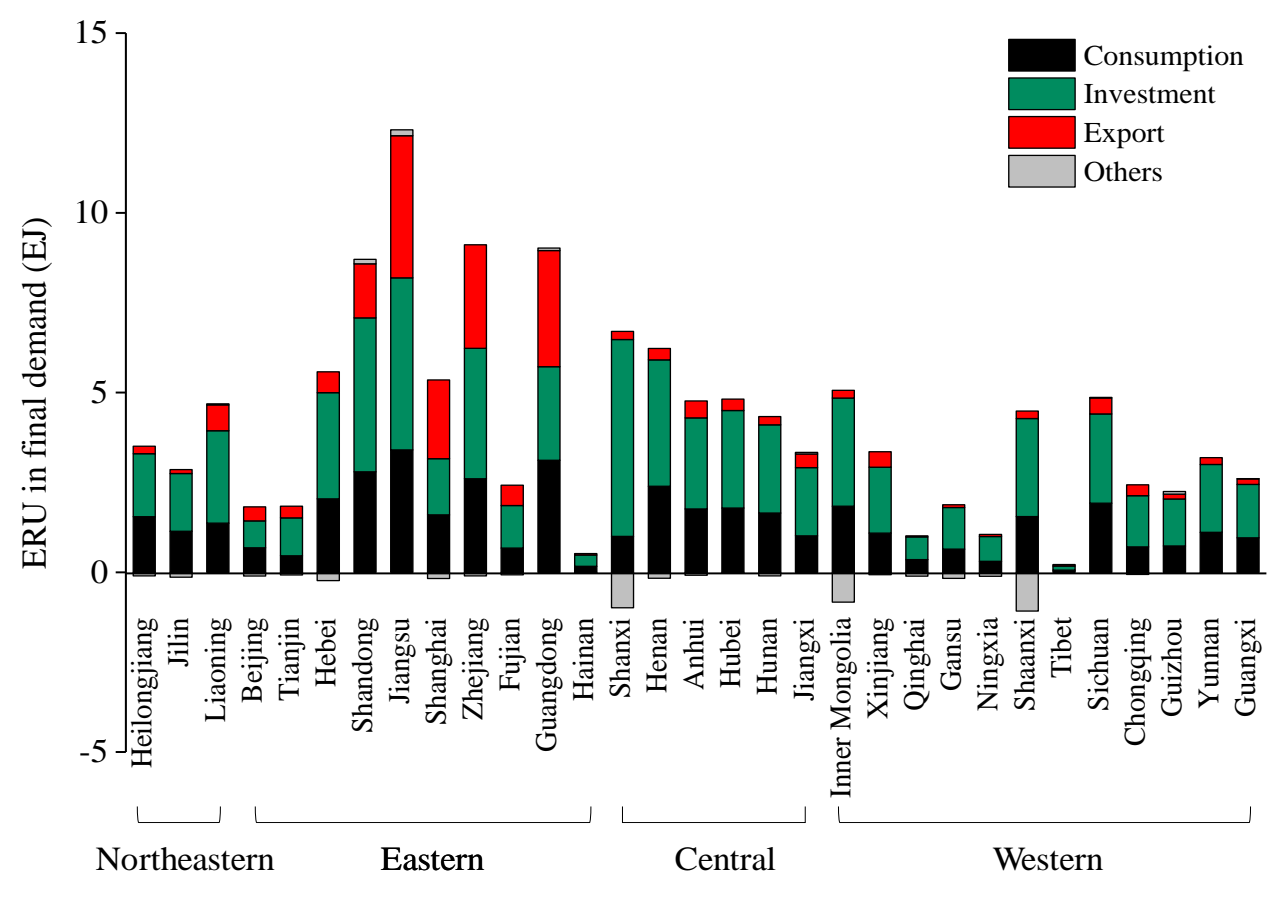

(a) By final demand category

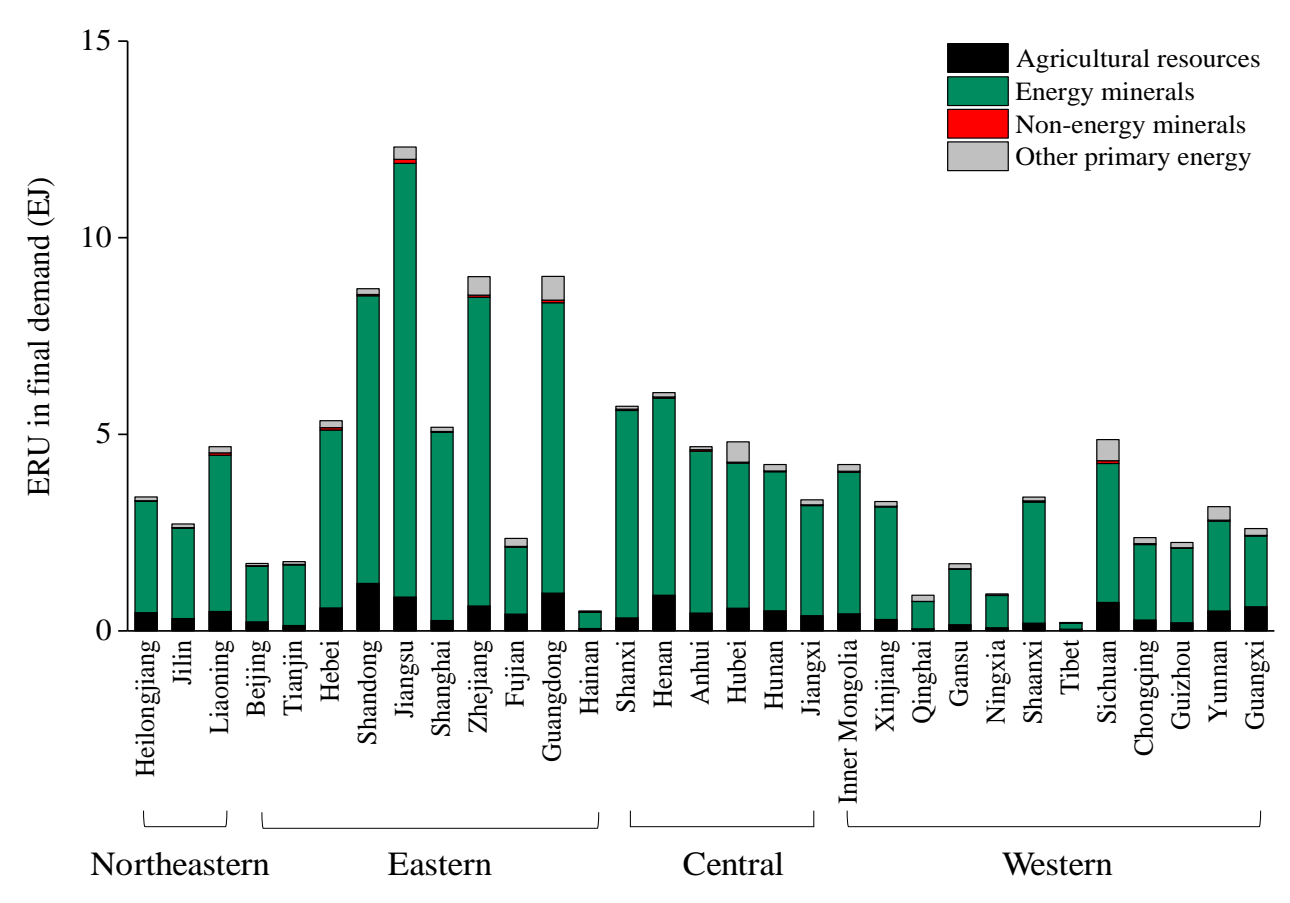

(b) By resource type

Fig. 2. Embodied resource uses (ERUs) in final demand by region. 


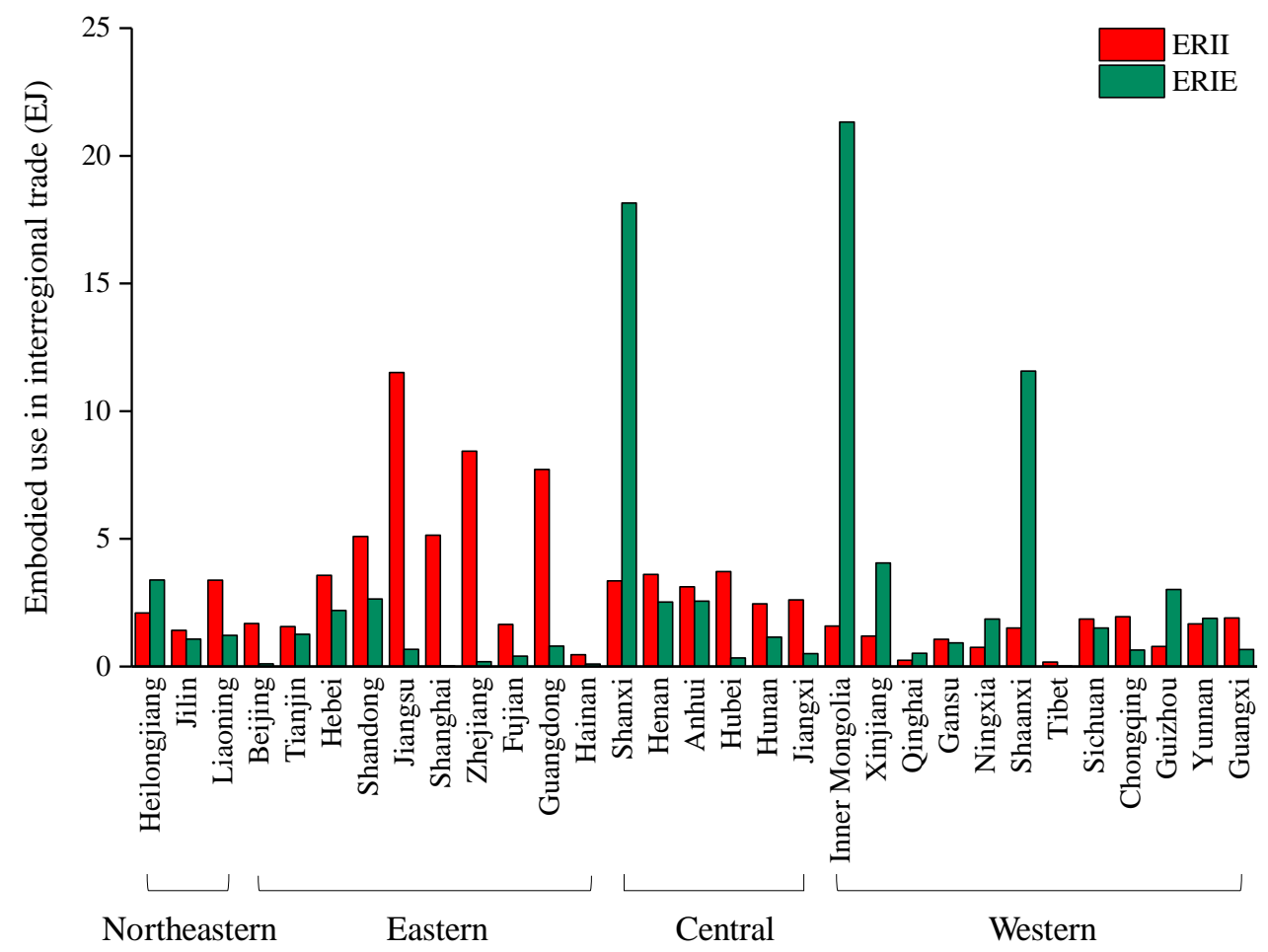

Fig. 3. Embodied resource uses (ERUs) in interregional trade by region. 


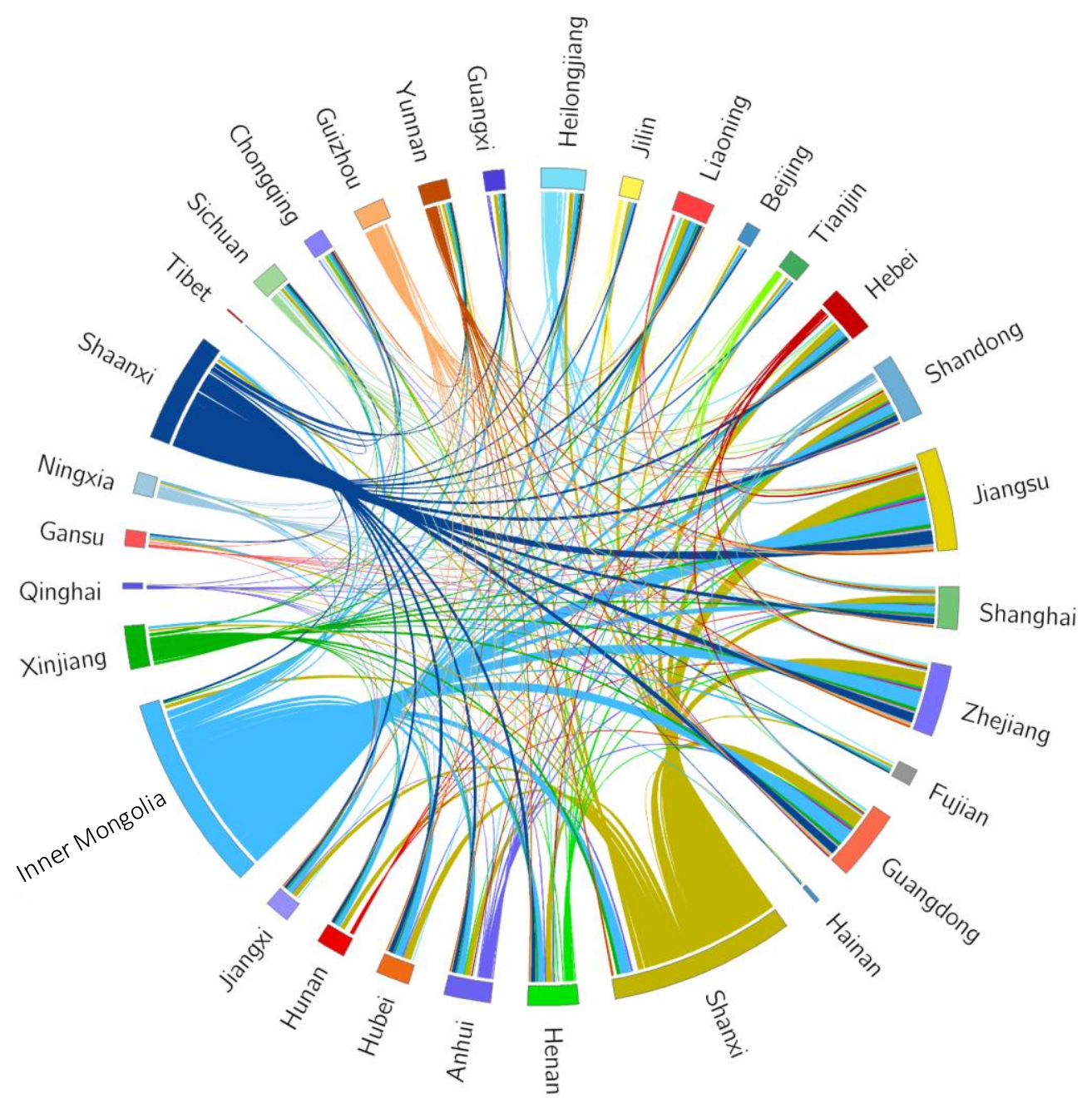

Fig. 4. Major embodied resource connections among 31 provincial regions. Note: The general trade relations between every two regions are portrayed by the chords. For each provincial region, the lines which have the same color with the outside arc stand for embodied resources in this region's export to other regions and the lines with other different colors stand for embodied resources in this region's import from other regions. 


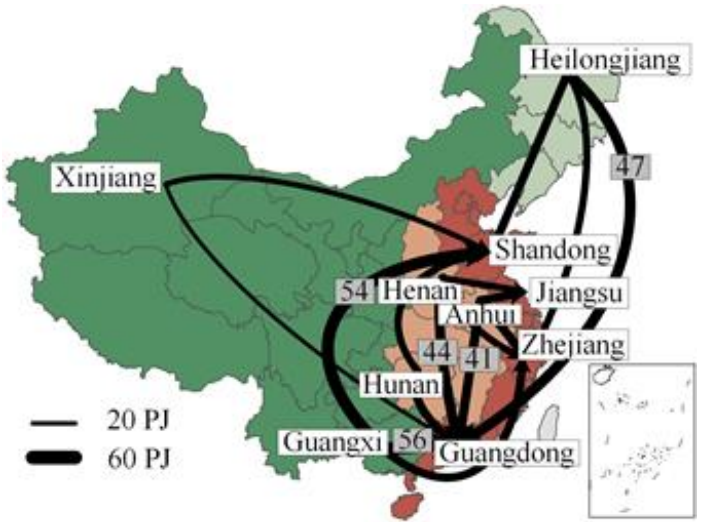

(a) Flux of agricultural resources

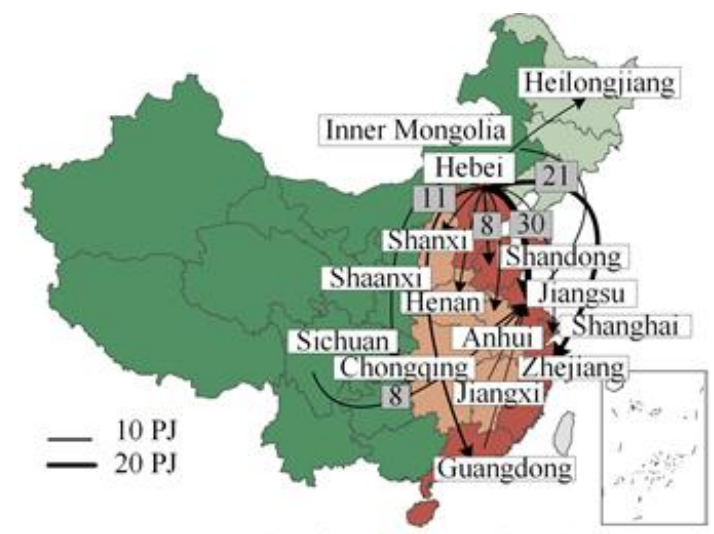

(c) Flux of non-energy minerals

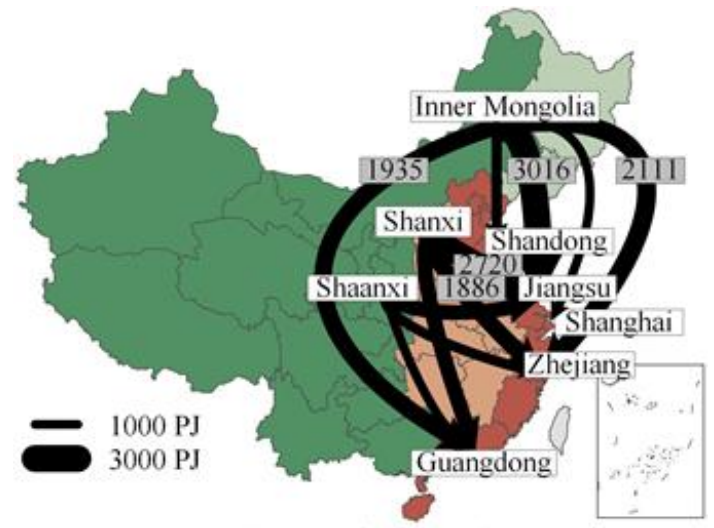

(b) Flux of energy minerals

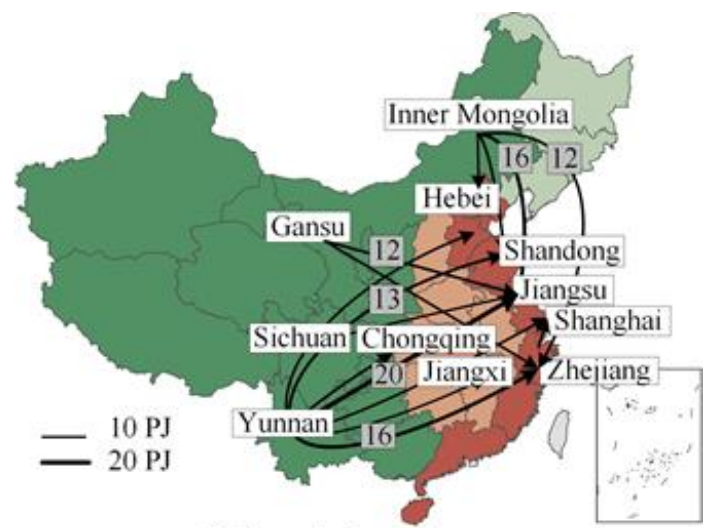

(d) Flux of other primary energy

Fig. 5. Major embodied resources fluxes of net interregional trade. Note: Four different colors represent four areas. The size of resource flow is represented by the thickness of solid line. 


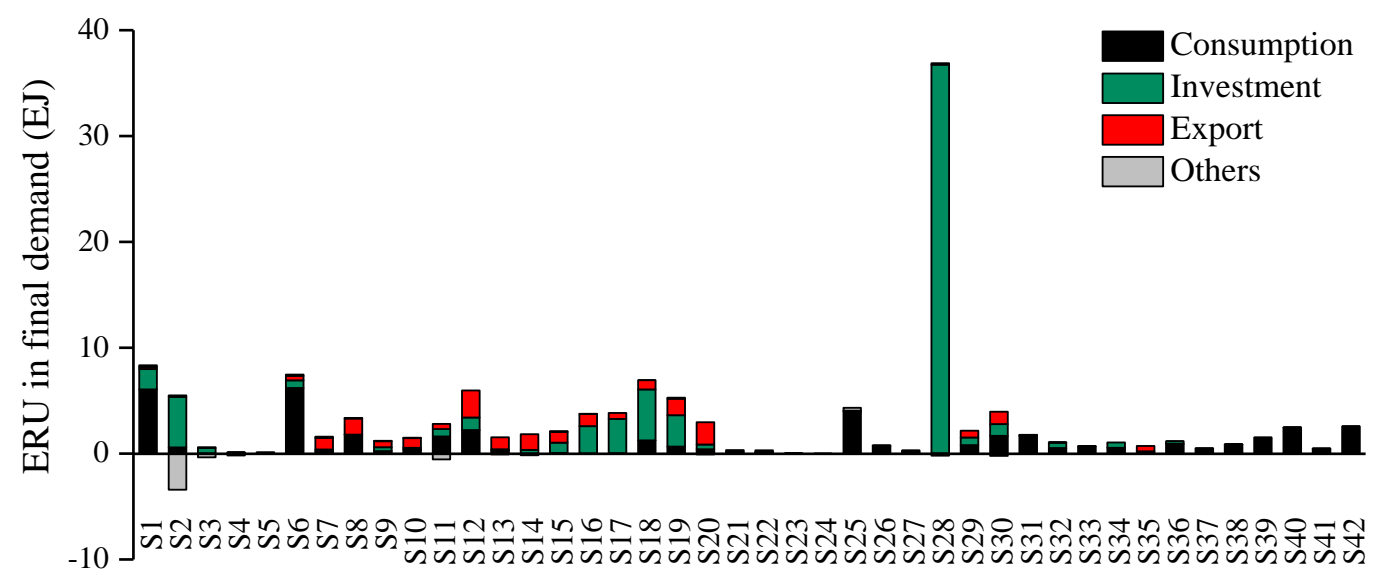

Fig. 6. Embodied resource uses (ERUs) in final demand by sector. 


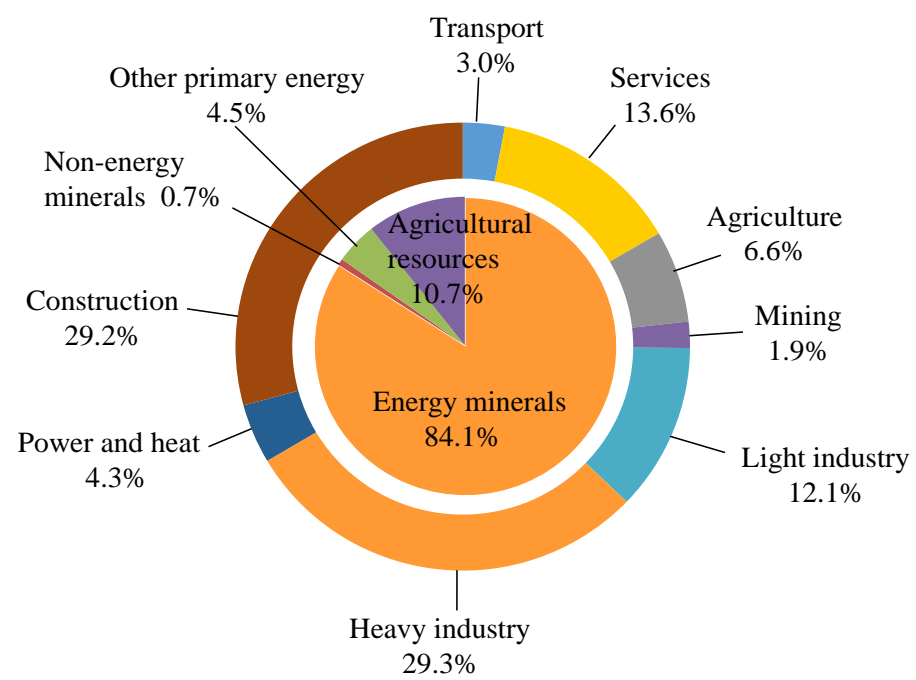

(a) ERUs in final demand.

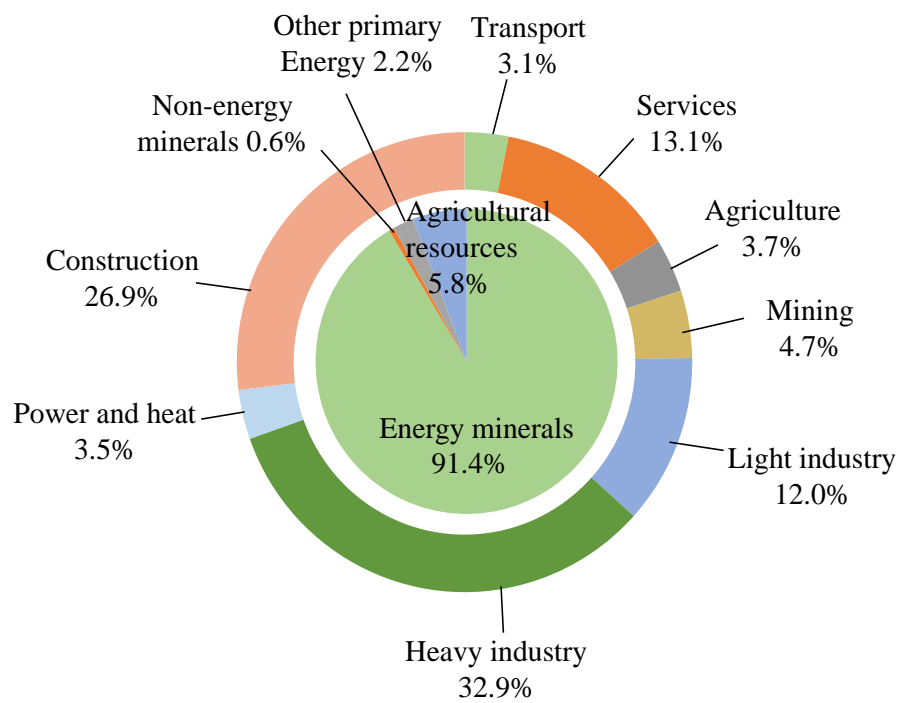

(b) ERUs in interregional trade.

Fig. 7. Compositions of embodied resource uses (ERUs) by resource category (Inner circle) and industry category (Outer circle). 


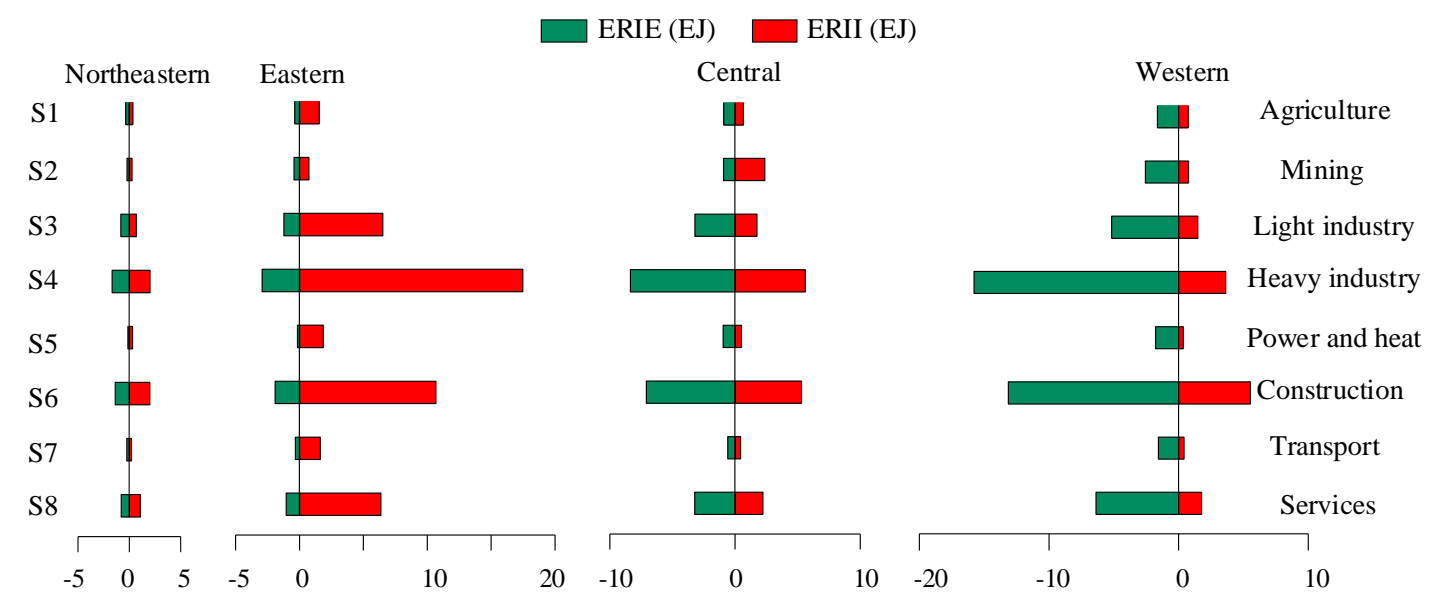

Fig. 8. Embodied resource uses (ERUs) in interregional trade of 8 industry categories in the four areas. 


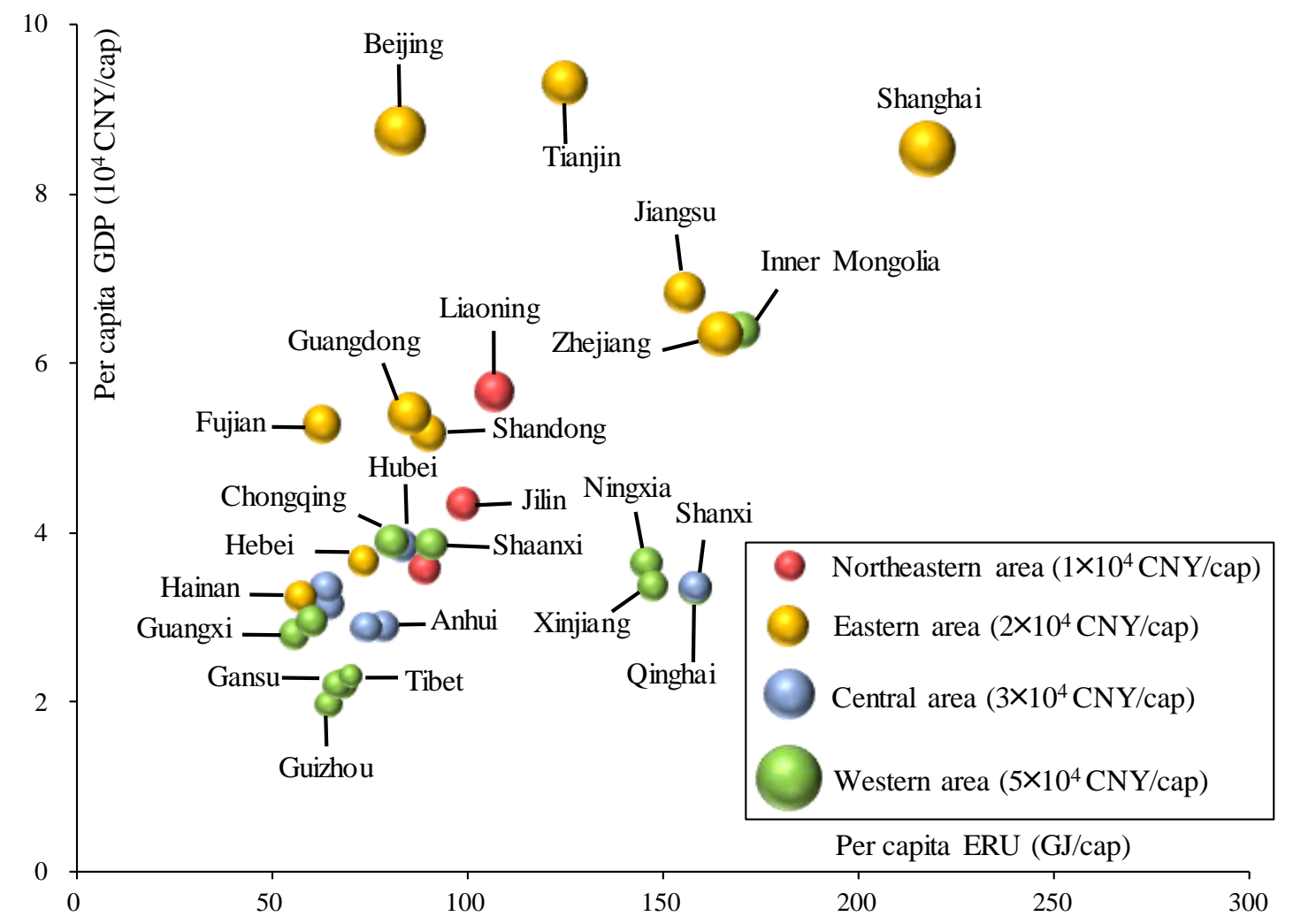

Fig. 9. The relationship between regional per capita GDP and per capita ERU. Note: The size of the sphere represents per capita household consumption expenditure. 


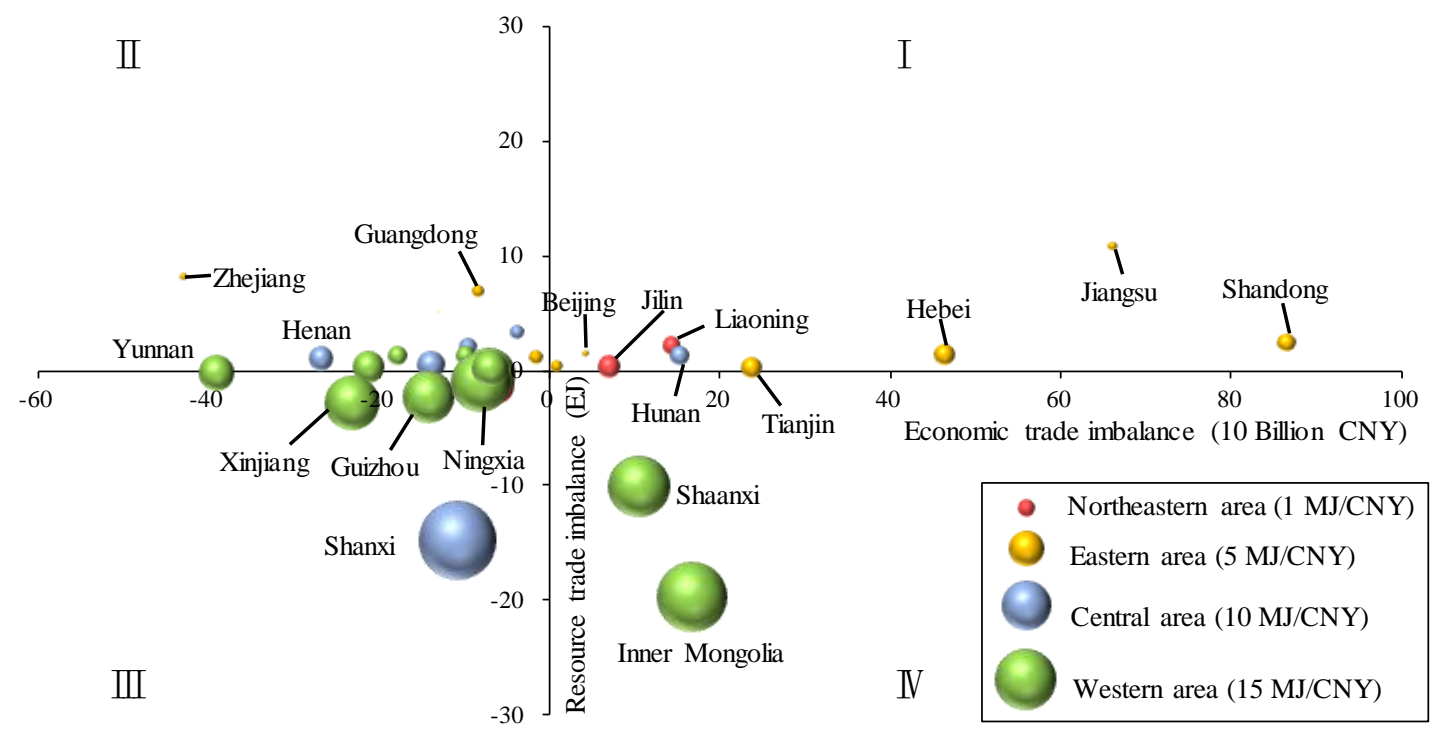

Fig. 10. Trade imbalance in terms of physical and economic flows by region. Note: The interregional net trade volume is used to indicate the scale of region's trade imbalance. The four quadrants in the rectangular coordinate represent four different trade patterns. Regions in the first quadrant are physical net importers and monetary surplus receivers; regions in the second quadrant are physical net importers and monetary deficit receivers; regions in the third quadrant are physical net exporters and monetary deficit receivers; and regions in the fourth quadrant are physical net exporters and monetary surplus receivers. The size of the sphere represents the ratio of regional gross physical export to its monetary volume of export trade. 
Click here to download Table: Tables.docx

\section{Tables}

Table 1. The categories of natural resource extracted in China 
Table 1

The categories of natural resource extracted in China

\begin{tabular}{|c|c|}
\hline Category & Content \\
\hline & Crops: rice, wheat, corn, millet, sorghum, bean, potato, peanut, rapeseed, \\
\hline & sesame, flaxseed, sunflower, cotton, hemp, sugarcane, tea leaf, tobacco leaf, \\
\hline & vegetable, melon, apple, pear, banana, orange, grape, pine apple, red date, \\
\hline
\end{tabular}

Agricultural resources

Forestry: timber, bamboo, rubber, pine resin, lacquer, tung-oil seeds, Tea-oil

seeds, forest food

Rangeland products: hay

Aquatic products: seawater aquatic products, freshwater aquatic products

Coal

Energy minerals

Crude oil, natural gas

Iron ore, copper concentrated, lead concentrated, zinc concentrated, alumina,

Non-energy minerals

Raw salt, pyrite, phosphorus ore, limestone, clay

Other primary energy Hydropower, nuclear power, wind power, other renewable energy 
Supplementary Interactive Plot Data (CSV)
Click here to download Supplementary Interactive Plot Data (CSV): Supplementary data.docx

Supplementary Interactive Plot Data (CSV)
Click here to download Supplementary Interactive Plot Data (CSV): Supplementary data.docx 